\title{
المجلد: (الثاني)
}

\section{العدد: (الخامس) ،يناير (2020)}

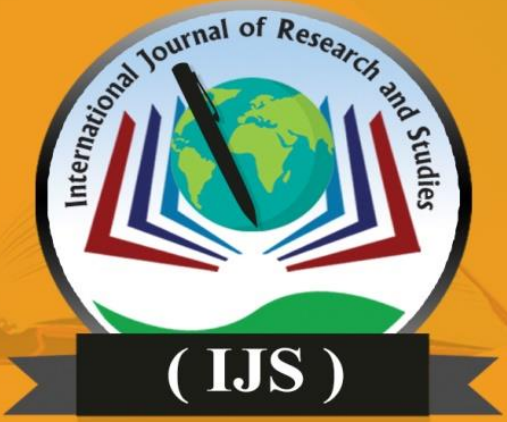

International Journal of Research and Studies

$$
\text { تصدروما آكاديمية }
$$




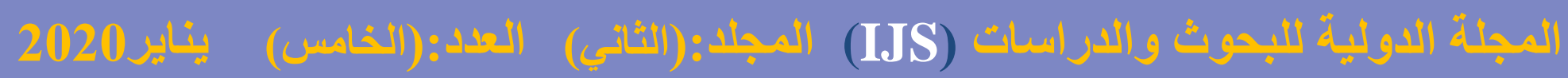

أ. د. رانيا الصاوي عبده عبد القوي، (عناصر العملية التعليمية ومهارات معلم القرن الحادي والعشرين).

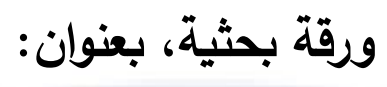

عناصر العملية التعليمية ومهارات معلم القرن الحادي والعشرين. إعداد: أ.د. رانيا الصاوي عبده عبد القوي.

أستاذ الصحة النفسية، جامعة القصيم، المملكة العربية السعودية.

مقدمة للؤتمر الدولي الأول، بعنوان: (الإدارة التربوية والتدريب والتنمية المهنية لمعلمي ومشرفي وقيادات الإدارة المدرسية في ضوء معايير التميز ومهارات القرن الإن لتربونه (الحادي والعشرين).

وتحت شعار: (جودة الإدارة التربوية والتدريب والتنمية البشرية).

برعاية أكاديمية رواد التميز للتدريب والاستشارات والتنمية البشرية.

المنعقد بمقر الأكاديمية بالقاهرة عبر القاعات الصوتية وبرنامج الزووم. في الفترة من 12-14 ربيع أول1441هـ، الموافق 9-11 1نوفمبر 2019م.

122

International Journal of Research and Studies (ijs) It is issued by the Excellence Pioneers Academy 


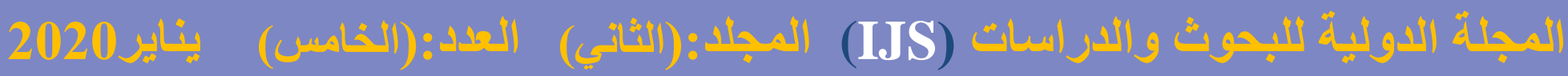

أ. د. رانيا الصاوي عبده عبد القوي، (عناصر العملية التعليمية ومهارات معلم القرن الحادي والعشرين).

\section{مقدمة:}

إن التعليم العام هو الذي يبدأ بتشكيل عقول المتعلمين وتوجيه اهتماماتهم، بل هو الذي يحفز الإلهام لديهم، فهو الذي يرسي القواعد المتينة للانطلاق نحو مجتمع المعرفة؛ فإذا ما استطاع أن يكون المنتج الأول للمعرفة فإن هذا يُعدُّ مؤشرًا لتحسين التعليم.

ولم تكن النظم التربوية، بصفة عامة، بمنأى عن تأثيرات عصر اقتصاد المعرفة، بل ربما كان ميدان التربية من أكثر الميادين تأثرًا بعصر اقتصاد المعرفة؛ إذ إن التربية بمؤسساتها هي مسرح تلقي المعرفة ونموها وتحليلها والربط بينها وبين تطبيقاتها المختلفة.

من هنا كان على النظم التربوية أن تديم النظر في مجال إعداد الأفراد وبناء مهاراتهم لمواكبة التغيرات بل ومبادأتها، والمعلم باعتباره الركيزة الأساسية الحاسمة في مدى نجاح جهود

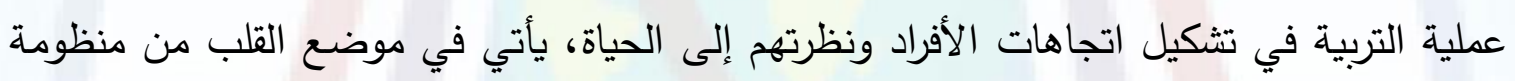
العناصر المتفاعلة في عملية التربية. ومن هنا يأتي التسابق المحموم على تطوير النظم التربوية بصورة شاملة لمواكبة التغيرات والتسارعات التي يشهدها هذا القرن.

عند الحديث عن دور النظام التربوي في إعداد الأفراد لـجتمع المعرفة، نجد أن التعليم العام يحتل قلب النظام التعليمي أينما وجد، كما أن مؤسسات التعليم تثكل عنصرًا رئيسًا في أي نظام تعليمي.

لذا يعد النظام التربويّ شديد الحساسيّة لِما يجري حوله من تغيُرات كما أشار (سعيد،2012:

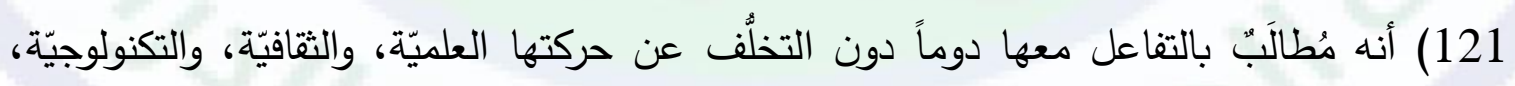
والمعرفيّة، حيث إنّ الحداثة الحقيقيّة ترتبطُ بجوهر العمليّة التربويّة، وترسيخ الروح العمليّة، وتعزيز

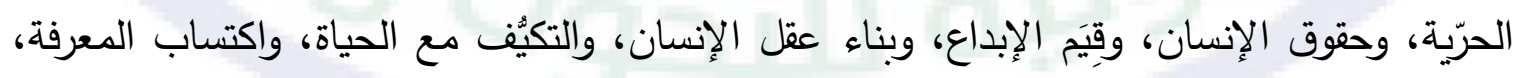
وتتمية القدرات الثخصيّة، وما إلى ذلك من أمور . 


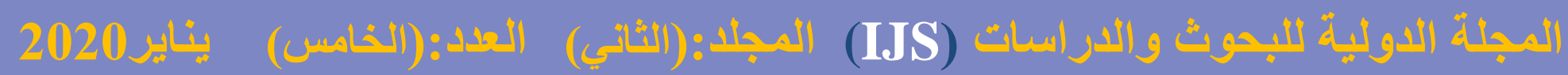

أ. د. رانيا الصاوي عبده عبد القوي، (عناصر العملية التعليمية ومهارات معلم القرن الحادي والعشرين).

$$
\begin{aligned}
& \text { لذا سوف نتناول في هذه الورقة البحثية ثلاث محاور أساسية: } \\
& \text { المحور الأول: عناصر العملية التعليمية. } \\
& \text { المحور الثاني: أبرز التحديات التي توجه معلم القرن الحادي والعشرين. }
\end{aligned}
$$

المحور الثالث: المهارات التي ينبغي أن تتوافر في معلم القرن الحادي والعشرين لإثراء العملية التربوية والتعليمية.

\section{المحور الأول: عناصر العملية التعليمية:}

تتكون العملية التعليمية من مجموعة من العناصر التي تتفاعل مع بعضها البعض ويؤثر ويتأثر كل عنصر في الآخر وترجع أهمية هذه العناصر في كونها الأساس التي تعتمد عليه العملية التعليمية لكل تتجح، وتحقق الأهداف المرجوة لذا نوضح أهم عناصر العملية التعليمية كما أشار إليها كل من: (الدريج، 2004، تونيزيا سات،2009، سالم،2010، الحربي، لهره

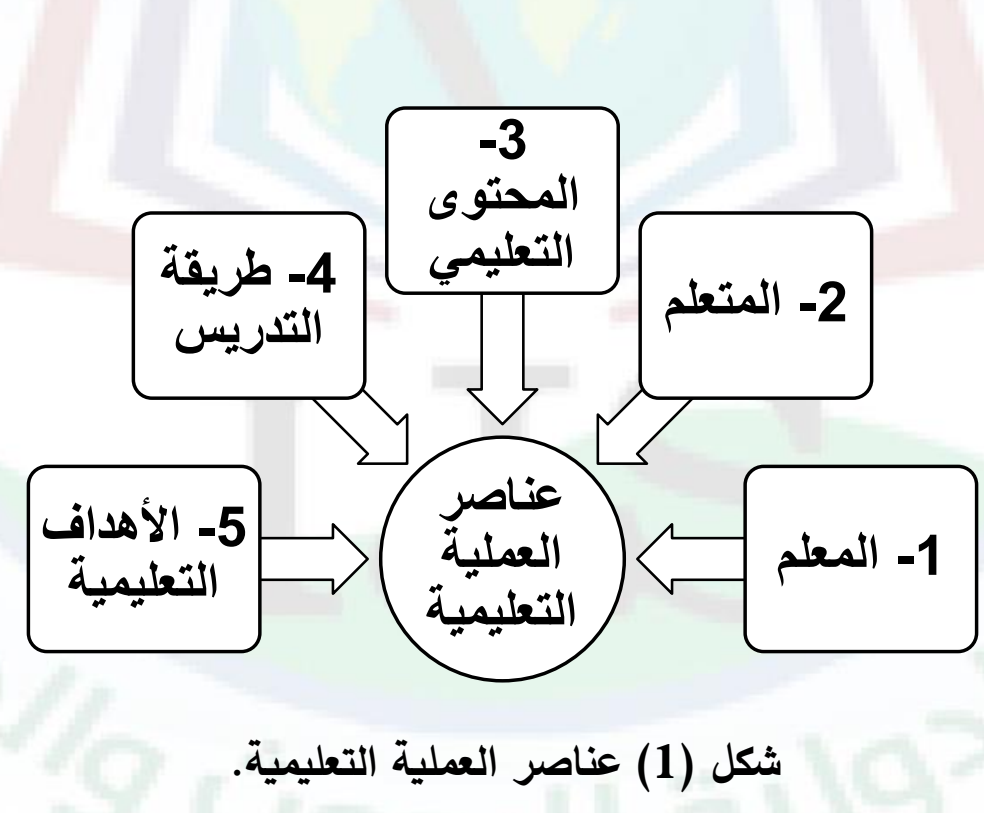




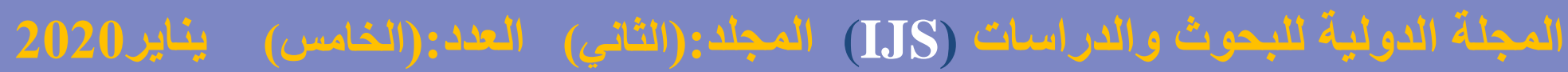

أ. د. رانيا الصاوي عبده عبد القوي، (عناصر العملية التعليمية ومهارات معلم القرن الحادي والعشرين).

أولاً: المُعلّمِ.

يلعب المعلم دوراً جوهرياً في هذه العملية، وذلك لأن يقوم بتحديد نوع المادة الدراسية، وما

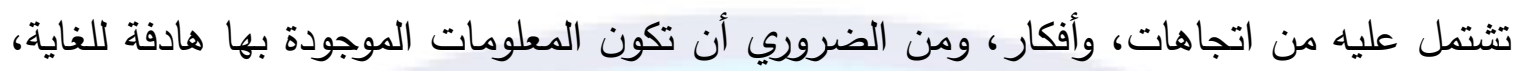
ولذلك يجب أن يتوافر به مجموعة من الثروط من أبرزها أن يكون المعلم متخصصاً، وعلى دراية

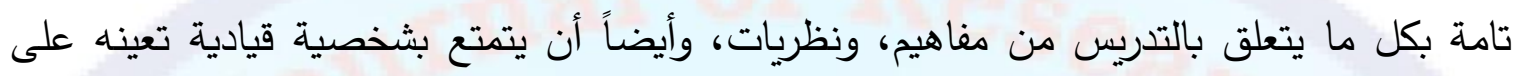

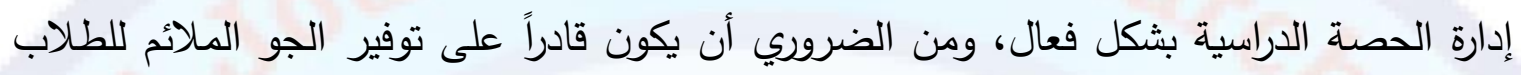
ولديه قدرة على الاستماع إليهم، وإدراك الفروق بينهم.

لذا يُعد المُعلّم أساس العمليّة التعليميّة؛ إذ إنّه يَينهي العقول، ويُربِّي الأجيال التي من شأنها أن

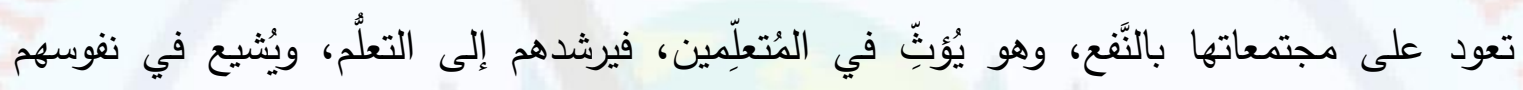

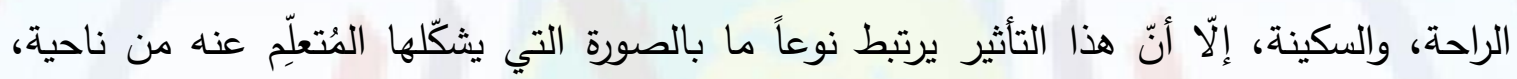
والصورة الحقيقيّة التي تتشكَّل؛ إثر الاحتكاك الحاصل بينهما في الواقع من ناحية أخرى.

ومن الجدير بالذكر أنّ المُعلّمِ هو القادر على معرفة جوانب الضعف، والقوة لدى طلبته، ممّا

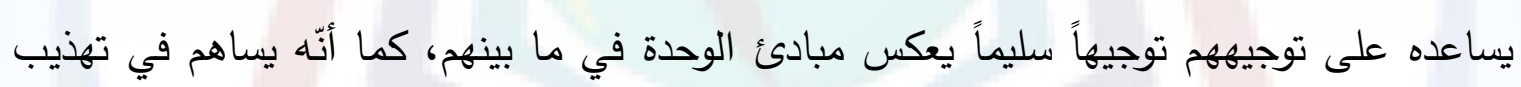

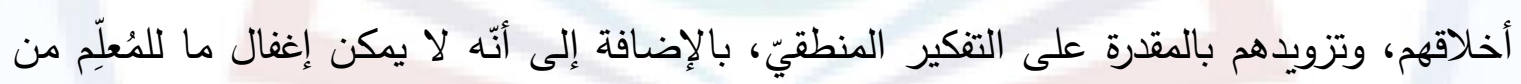

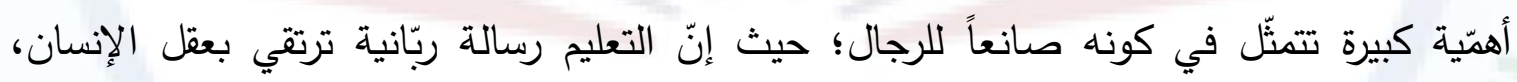

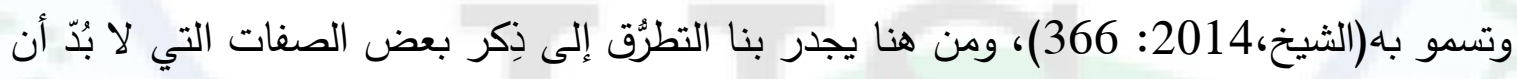

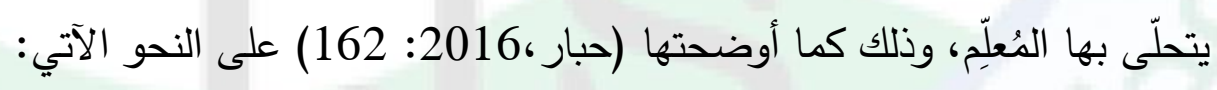
• التمكُن من المادّة التعليميّة التي يُدرِِّها، وإدراكَ أهمّ مصادر المعلومات المُرتبطة بها. • التمتُّع باللغة السليمة، وغير المُعُقَّة.

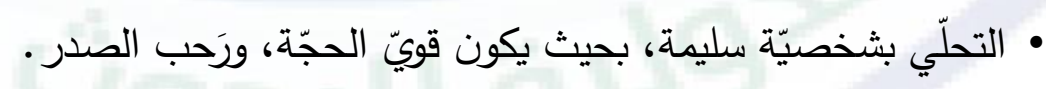

• تفهّم ميول الطلبة، وطبائعهم، واستعداداتهم، وخلفيّاتهم.

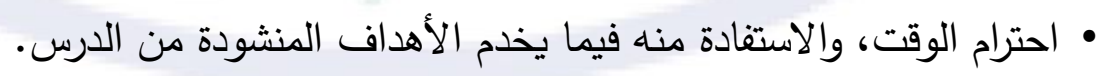
• مراعاة الفروق الفرديّة بين الطلبة، وإشراكهم جميعهم في الدرس. 


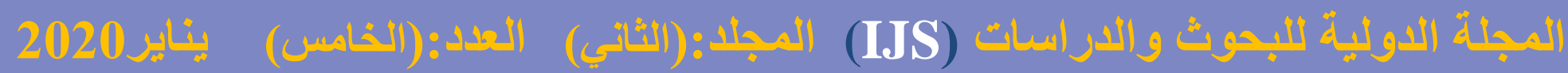

أ. د. رانيا الصاوي عبده عبد القوي، (عناصر العملية التعليمية ومهارات معلم القرن الحادي والعشرين).

ثانياً: المُتُعِّم.

هو المتعلم الذي تقوم العملية التعليمية من أجله، ولذلك من الضروري أن يكون لديه رغبة

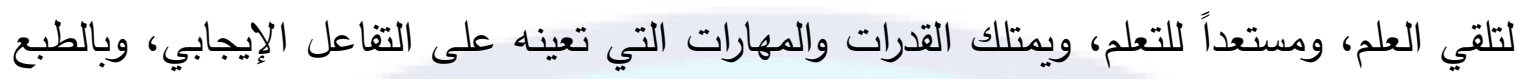
وفقاً لاستعداد الطالب، وما يملكه من قدرات ومهارات تتحد الأنشطة، والأساليب التي سيتم الاعتماد عليها من أجل الوصول للأهداف المرجوة.

كما يتعرَّض الكُتعلّم خلال نموّه النفسيّ، والجسديّ، والعقليّ للعديد من المراحل التي يكتسب من

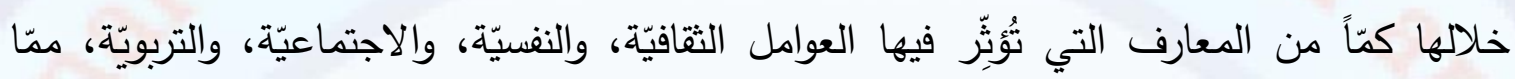
يجعل عمليّة التدخُل؛ لتعديل هذه العوامل، وتعزيزها أمراً ضروريّاً؛ بهدف تثكيلها؛ ولتحقيق هذا، فإنيّه

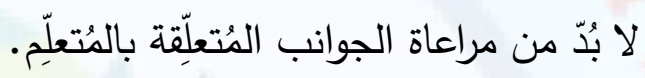

وهي في الوقت نفسه تُعدُّ عوامل نجاح العمليّة التربويّة؛ إذ تتضمّن العوامل المعرفيّة، والنفسيّة،

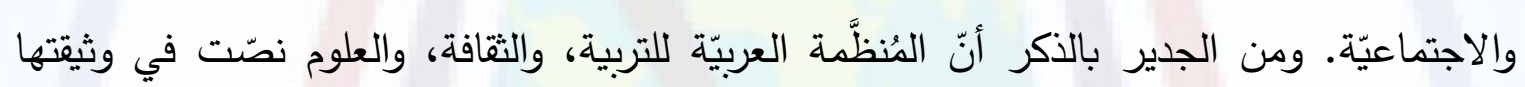

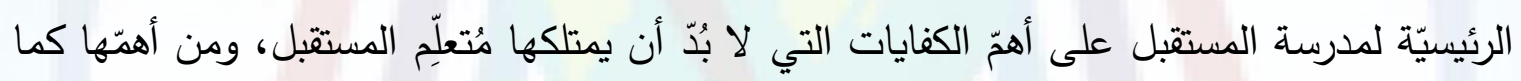

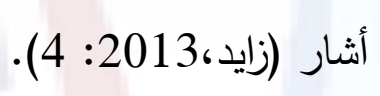

• • الحفاظ على الهويّة الدينيّة، والقوميّة، والوطنيّة، والثقافيّة. • التحلّي بمهارات التواصل الحضاريّ، والثقافيّ. • التحلّي بمهارات التفكير الناقد، والحوار مع الآخرين، والنقد البنّاء، وغيرها.

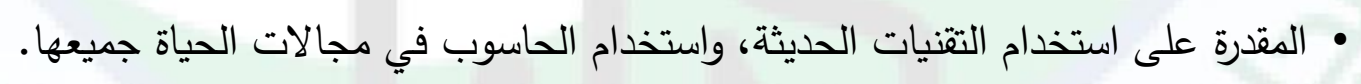
• التحلّي بروح الفريق، والمبادرة، والإبداع، والتعاون، والتحلّي أيضاً بالأخلاقيّات.

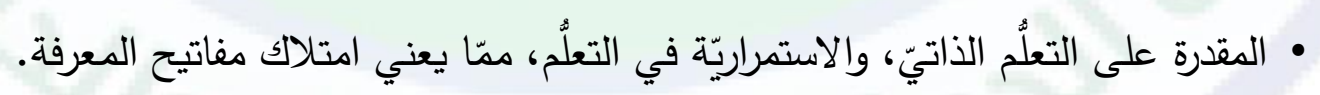

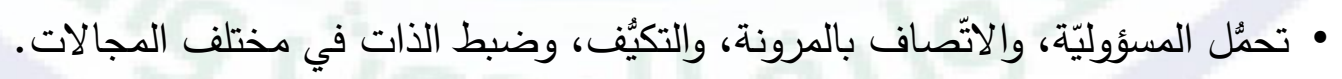
• المقدرة على اتِّاذ القرارات، وحلّ المشكلات، والتخطيط للمستقبل. • المقدرة على البحث، وتحليل المعلومات، وإتقان مهارات اللغة العربيّة، مع الحرص على استخدام 


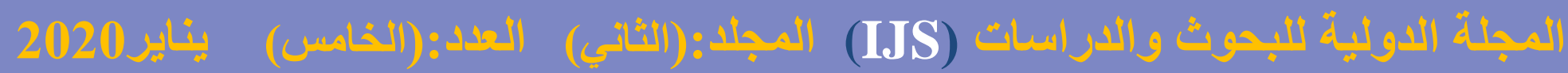

أ. د. رانيا الصاوي عبده عبد القوي، (عناصر العملية التعليمية ومهارات معلم القرن الحادي والعشرين).

ثالثاً: المُحتوى التعليميّ.

هناك العديد من التعريفات التي تتاولت المحتوى التعليمي مثل (Peat Mary:2000) Safa Naser Husain:2012)، ويمكن تعريفه على أنه مجموعة أفكار ، وحقائق معبرة عن الثقافة التي تنتشر في مجتمع ما، وفي التعليم يعرف ذلك المحتوى بالمناهج أو المقررات الدراسية ويتم تصنيفها كالتالي (اللغات، والدراسات الاجتماعية، والفلسفة، ومن الضروري أن تكون هذه المناهج تتاسب مستوى الطلاب، وتراعي كافة الفروق بين كل طالب، وآخر .

لذا يُعَدُ المنهاج تكامُليّاً؛ نظراً لأنّ المعرفة غير مُحدَّدة بموضوعات مُعيَّنة، ممّا يساعد على استخدام نماذج من الواقع؛ لعرض، وتحليل، وتطبيق، وتتييم مفاهيم خاصّة، وعامّة؛ في سبيل دمج

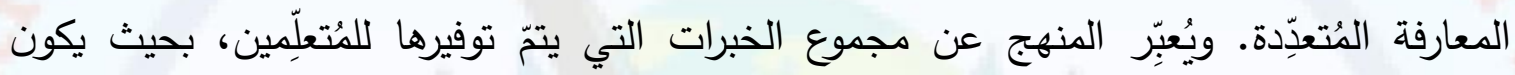

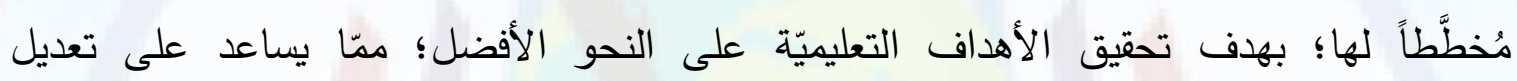

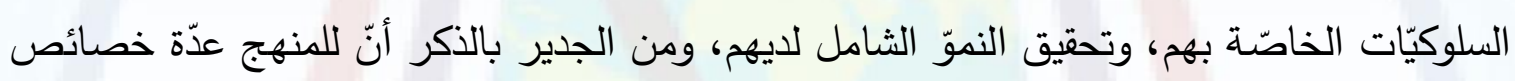

$$
\text { يذكر منها (خطاب، 2012: 136-137) ما يأتي: }
$$

• مساعدة المُتمعِمِين على التكيُّف مع التغيُرات الحاصلة في المجتمع، وتتقبُلها. • التتوُع في مصادر المعرفة، بحيث لا يتمّ الاقتصار على الكتاب المدرسيّ وحده. • مراعاة احتياجات المُتعِّمِين، وحلّ مشكلاتهم.

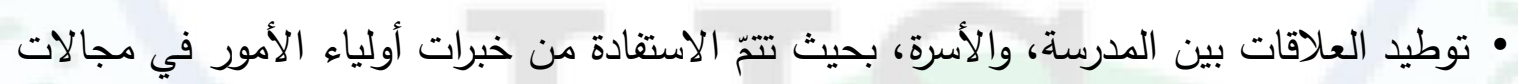
مُحدَّدة، ومراعاة واقع المجتمع، وفلسفته.

• مساعدة الكُتعِّمِين على اكتساب العادات الحسنة، والقِيَيَ، وتعزيز التعاون فيما بينهم. • الاستمراريّة، والتتوُع في التقييم. • استثارة الدوافع الخاصِّة بالمُتعِّمِين نحو التعلُّم، وتعزيز التعلُّم الذاتيّ لديهم. • مراعاة الفروق الفرديّة بين المُتعلّمين. • التتوُّع في أساليب، وطرائق التدريس، بما يتتاسب مع طبيعة التلاميذ، وطبيعة المحتوى. • تحقيق التكامل ما بين الجوانب النظريّة، والتطبيقيّة.

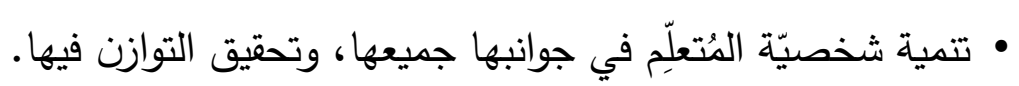




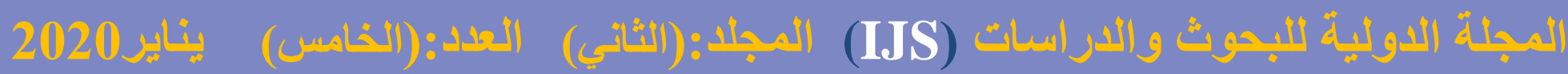

أ. د. رانيا الصاوي عبده عبد القوي، (عناصر العملية التعليمية ومهارات معلم القرن الحادي والعشرين).

رابعاً: طريقة التدريس.

يمكن تعريف الطريقة على أنها الأسلوب المميز الذي يعتمد عليه المعلم لتحقيق أهداف

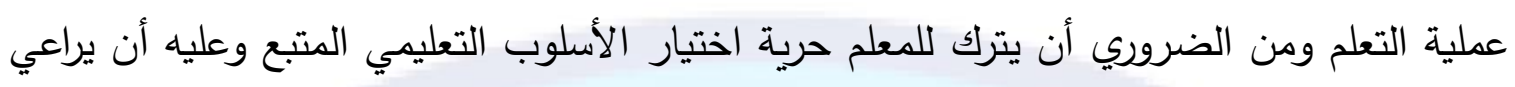

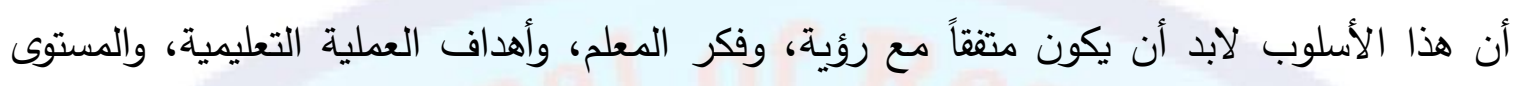
الفكري للطلاب ووعيهم.

وتُعرَّف طريقة التدريس على أنهّا: مجموعة من الإجراءات، والخطوات الكُترابطة، والتي يتّبعها

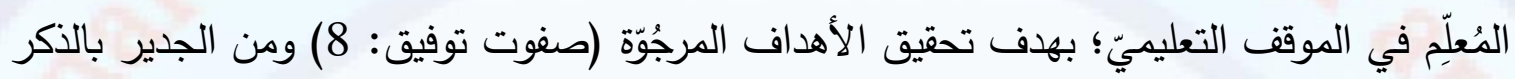
أنّ طرائق التدريس تثمل عدّة أشكال، منها: طريقة الإلقاء، والطريقة الاستنباطيّة، والطريقة الاستقرائيّة، والطريقة التكامُليّة، والطريقة الحواريّة، وطريقة المشروع، وطريقة حلّ المشكلات، علماً

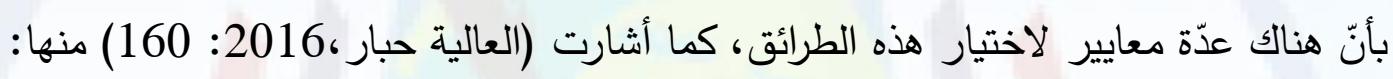
• مراعاة طبيعة المادّة الدراسيّة. • مراعاة عدد المُتعلّمِين في الصف الدراسيّ. • ت توفُرْ الوسائل التعليميّة، وتنوُعها. • توفُّر الوقت الكافي؛ لتحقيق الأهداف التعليميّة. • مراعاة العُمر الزمنيّ للمئتعِمِين، والمرحلة الدراسيّة. • مراعاة طبيعة الأهداف التعليميّة. خامساً: الأهداف التعليميّة.

ويُعرَّف الهدف بحسب (Mager) على أنّه: "مقصد مصوغ في عبارة تصف تغيُراً مُقترَحاً يُراد

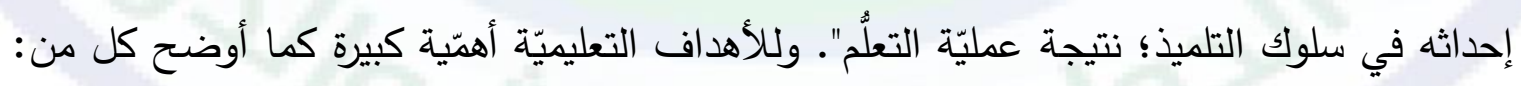
(الخطيب:1988، سعادة:1991، جان:1998) تتمثّل في أنّها:

• تساعد في عملية تخطيط الأنشطة التعليميّة المطلوبة. • يمكن استخدامها في تحديد الوسائل التعليميّة، وأساليب التدريس الملائية. • تُعَدُ دليلاً للمُعلّمٍ في تخطيط درسه اليوميّ.

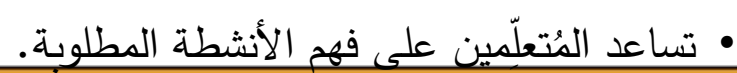




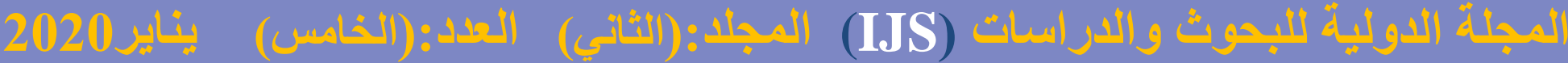

أ. د. رانيا الصاوي عبده عبد القوي، (عناصر العملية التعليمية ومهارات معلم القرن الحادي والعشرين).

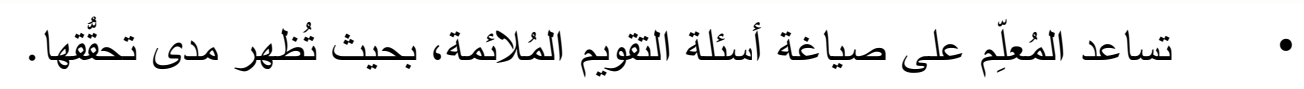
أمتا فيما يتعلَق بمصادر الأهداف التربويّة كما أثار إليها كل من: (تونيزيا سات:2009، سالم:2010، خطاب:2012) فهي تتبثق ممّا يأتي:

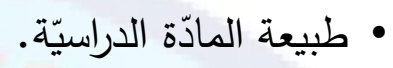
• وجهات نظر المُتخِِّصين في الميدان التربويّ، وميدان علم النفس.

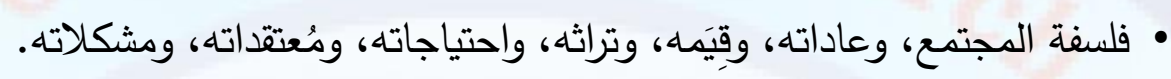

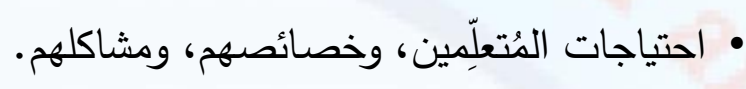

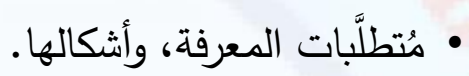

كما أنّ الأهداف تندرج ضمن عدّة مستويات كما أشار كل من: (كريم، بدران :1997: أبو العنين

$$
\text { واخرون:2004، شريف:2005) هي: }
$$

• أهداف عامَّة للتربية: وهي تتَّفف بكونها بعيدة الددى، ومُجرَّة، وعامَّة، وواقعيّة، وشاملة،

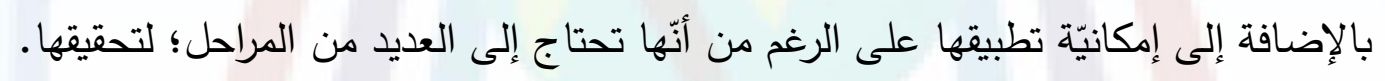

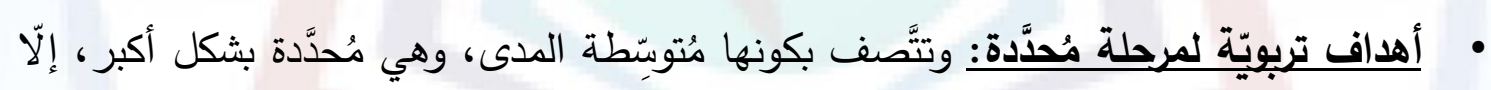

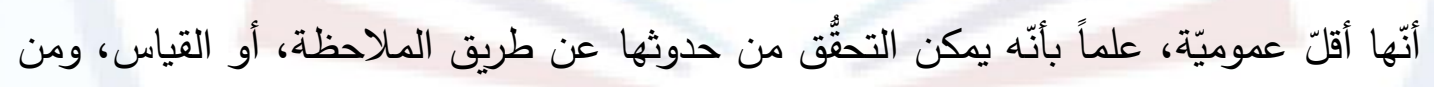

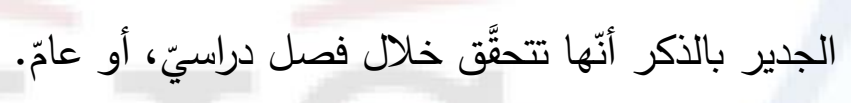

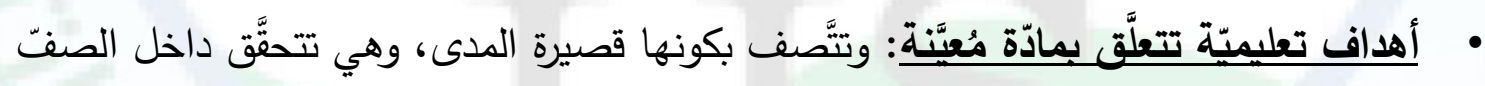

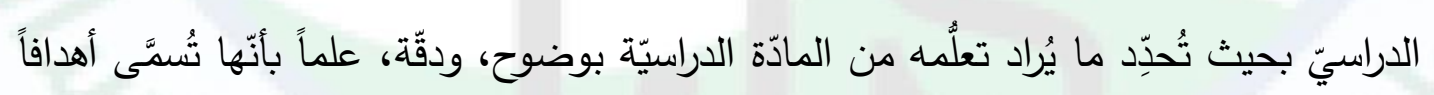

$$
\text { سلوكيّة عند صياغتها بطريقة إجرائيّة. }
$$

وبالنظر إلى معايير اختيار الأهداف، فإنْها تشمل كما أشارت (صبري:2010) ما يأتي:

• أن تكون شاملة لمجالات الأهداف التزبويّة جميعها.

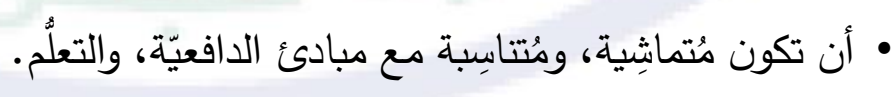

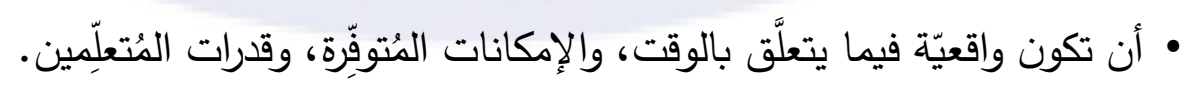

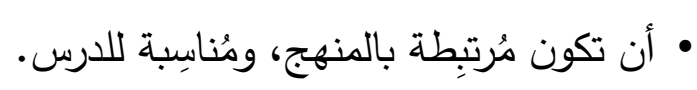




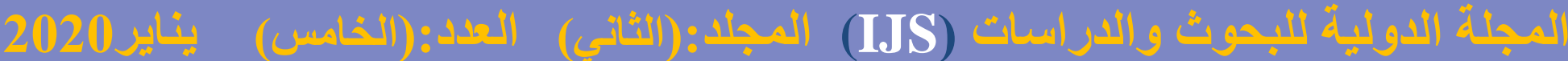

أ. د. رانيا الصاوي عبده عبد القوي، (عناصر العملية التعليمية ومهارات معلم القرن الحادي والعشرين).

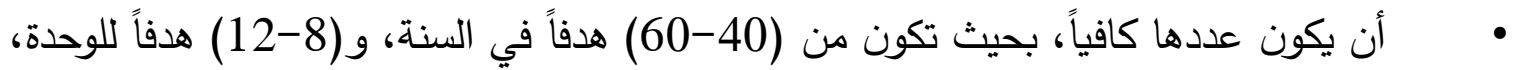

$$
\text { و) و-1-3 أهداف في الحصّة الدراسيّة. }
$$

لذا فإن تفاعل جميع العناصر سالفة الذكر مع بعضها البعض يؤدي في نهاية الأمر إلى تحقيق الأهداف المرجوة وفي حالة وجود تقصير أو خلل في أحد العناصر سوف يؤدي ذلك إلى وجود خلل في العملية التعليمية بأكملها. المحور الثاني: التحديات التي تواجه معلم القرن الحادي والعشرين. هنالك العديد من التحديات التي تواجه معلم القرن الحادي والعشرين التي أشار إليها كل من: (الزهراني، إبراهيم:2012) نجملها في الثكل التالي:

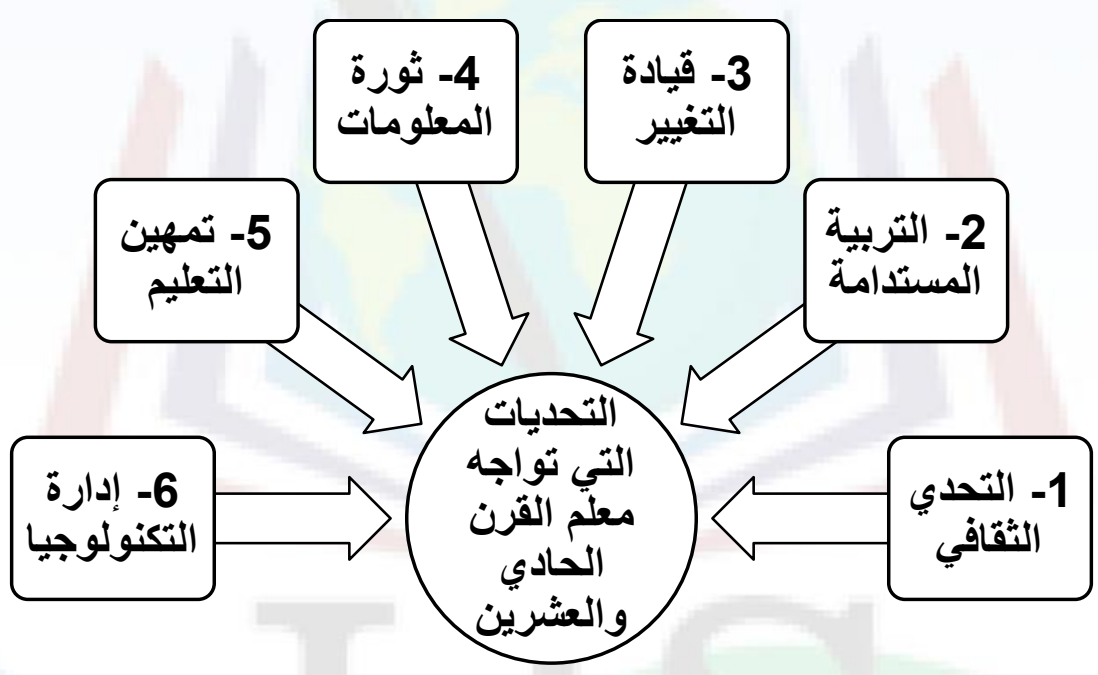

شكل (2) التحديات التي تواجه معلم القرن الحادي والعشرين.

أولًا: التحدي الثقافي:

يشهر العصر الحالي الصراع الثقافي الذي يهدد سلوكيات وقيم المجتمعات، ومن هنا يصبح المعلم مطالبًا بدوره في تعميق شعور الطالب بمجتمعه وتوضيح القيّم من الرخيص لله مما يبث عبر

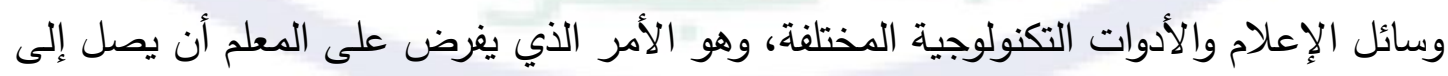




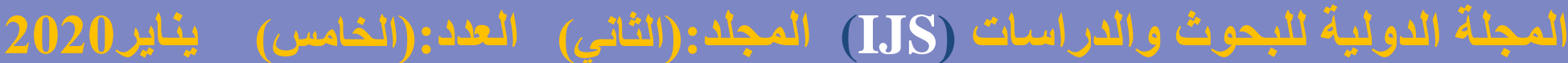

أ. د. رانيا الصاوي عبده عبد القوي، (عناصر العملية التعليمية ومهارات معلم القرن الحادي والعشرين).

استيعاب الثقافة العالية ليستطيع تحقيق هدفين أساسيين مع طلابه هما:

$$
\text { 1- دعم الهوية الثقافية للمجتمع العربي والإسلامي. }
$$

2- شرح الخطط الوطنية والقومية وتعزيز الأفكار والقيم الإيجابية السائدة في المجتمع.

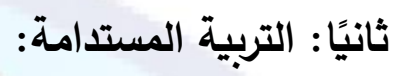

التربية المستدامة هي تربية تمتد طوال الحياة في أوقات وأماكن متعددة خارج حدود المدرسة

النظامية، ويصبح المعلم مطالبًا بمراعاة ثلاثة جوانب لتحقيق هذه التربية:

1- التعلم للمعرفة: والذي يتضمن كيفية البحث عن مصادر المعلومات وتعلم كيفية التعلم للإفادة

$$
\text { من فرص التعلم مدى الحياة. }
$$

2- التعلم للعمل: والذي يتضمن اكتساب المتعلم الكفايات التي تؤهله بشكل عام لمواجهة المواقف

$$
\text { الحياتية المختلفة، وانتقاء مهارات العمل. }
$$

3- التعلم للتعايش مع الآخرين: والذي يتضمن اكتساب المتعلم لمهارات فهم الذات والآخرين، وإدراك

أوجه التكافل فيما بينهم، والاستعداد لحل النزاع، وإزالة الصراع، وتسوية الخلافات.

ثالثًا: قيادة التغيير:

المعلم هو القائد الفعلي للتغيير الجوهري في المجتمع، وتغرض قيادة التغيير على المعلم اتباع نموذج واضح وأسلوب تفكير عقلاني منظم يساعده على استشراف آفاق المستقبل واستشعار نتائج عملية تطبيق التغيير المقترح في العملية التعليمية، وبالتالي إدخال تغييرات مخطط لها لضمان نجاحها. إن مهنة المعلم في المستقبل أصبحت مزيجًا من مهام القائد، ومدير المشروع والناقد

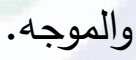

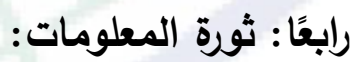

لقد أحدثت ثورة الاتصالات وتكنولوجيا المعلومات ونظمها تغييرات واسعة ومهمة جدًا، وبدأت القيم النسبية للمعرفة تبرز في مجتمع عالمي يتوجه نحو الاقتصاد المعرفي، وبالتالي تزايدت أعباء المعلم الذي لم يعد مطلوبًا منه الاكتفاء بنقل المعرفة للمتعلم، بل أصبح المطلوب منه تتمية لتهية 


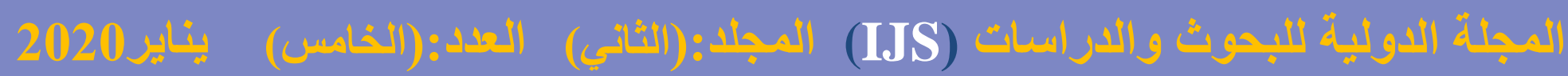

أ. د. رانيا الصاوي عبده عبد القوي، (عناصر العملية التعليمية ومهارات معلم القرن الحادي والعشرين).

قدرات المتعمين على الوصول للمعرفة من مصادرها المختلفة، وكذلك الاستثمار الأمثل للمعلومات من خلال البحث عن الطرق الفعالة معها لتحقيق أقصى استفادة ممكنة.

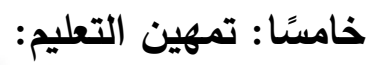

نحن بحاجة لثورة لتمهين التعليم، وتتمثل تلك الثورة في اتخاذ السبل الكفيلة بجعل التعليم

مهنة ترقى لهصاف المهن المرموقة والمتميزة في المجتمعات العربية كالطبيب والمهندس، ويتطلب التمهين توافر ثقافة واسعة وقدرات متميزة لدى المعلم كالاستقلالية في اتخاذ القرار، والحرية في الاختيار ، والمعرفة المتميزة، والاستخدام المتقدم للتكنولوجيا، والتحول إلى المصدم المحترف لبيئة

التعليم وأدواتها.

سادسًا: إدارة التكنولوجيا:

لم يكن لأهل التربية القائمين على تيسير سبل التعلم أن يقفوا مكتوفي الأيدي إزاء هذا التقدم الهائل في مجال تكنولوجيا المعلومات، فإن هذا التقدم الهائل في تكنولوجيا المعلومات، ووسائل لئل التعامل معها في هذا العصر الذي يتسم بالمعلوماتية، ومع ظهور شبكة المعلومات الدولية (Internet)

وأصبح التعليم يواجه عددًا من التحديات التي تتطلب إمداد عناصر العملية التعليمية البشرية بالمهارات اللازمة لمواجهة هذه التحديات، ومن ثم ظهر في الساحات التربوية مفهوم جديد يعرف بتكنولوجيا التعليم، الذي ما لبث أن حدث بينه وبين مفهوم تكنولوجيا المعلومات تجانسًا كبيرًا أدى إلى ظهور أنماط تعليمية جديدة أطلق عليها المستحدثات التكنولوجية التعليمية.

ويهدف إكساب المعلمين لمهارات التعامل مع هذه المستحدثات تغيير نمط ما يقدم للمعلمين

من المعلومات باعتبارها هدفًا إلى اكتساب مهارات حياتية جديدة تجعلهم يوظفون المعلومات،

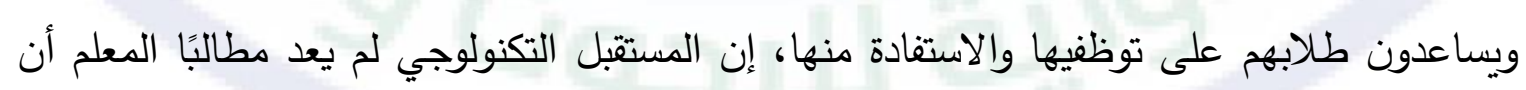

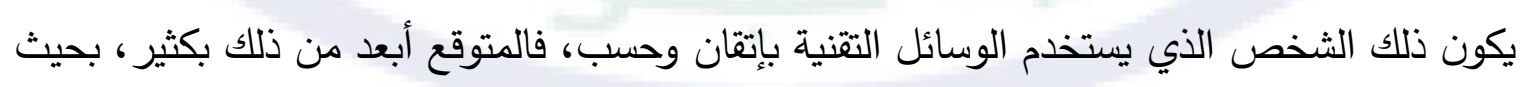

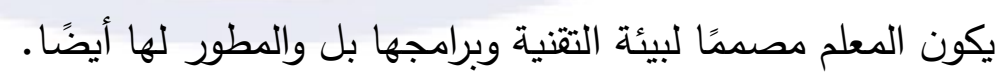

132

International Journal of Research and Studies (ijs) It is issued by the Excellence Pioneers Academy 


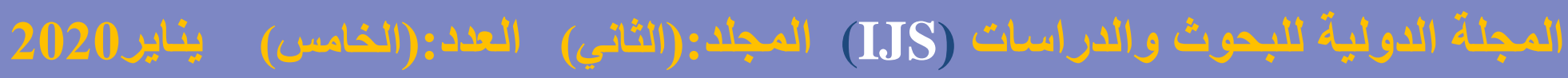

أ. د. رانيا الصاوي عبده عبد القوي، (عناصر العملية التعليمية ومهارات معلم القرن الحادي والعشرين).

المحور الثالث: المهارات التي ينبغي أن تتوافر في معلم القرن الحادي والعشرين لإثراء العملية التربوية والتعليمية.

هناك العديد من المصادر التي يمكن أن نستقي منها المخطط العام لمهارات معلم القرن الحادي والعشرين وأشار إليها كل من: ( Ananiadou, K. \& Claro, M. 2009 Trilling, B., Ananiadou, K. and M. ،Trilling, B., \& Fadel, C. 2009 ،\& Fadel, C. 2009 Claro 2009 (Schleicher, A. نجملها في الثكل التالي: 2013

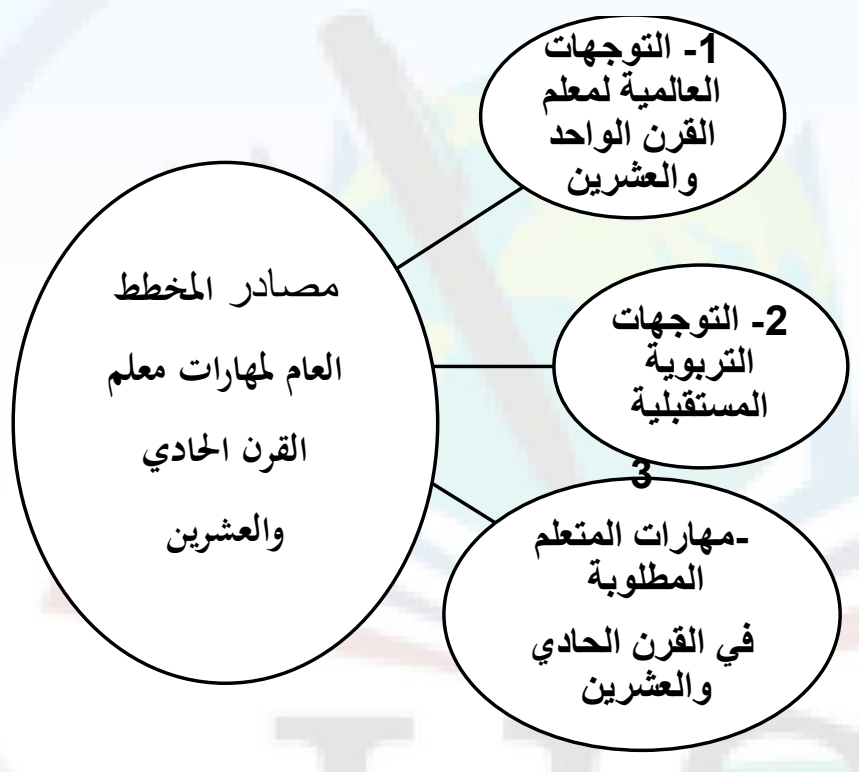

شكل (3) مصادر المخطط العام لمهارات معلم القرن الحادي والعشرين. المصدر الأول: التوحهات العالمية لمعلم القرن الحادي والعشرين. بالرجوع إلى التوجهات العالمية لتحديد مواصفات معلم القرن الحادي والعشرين نلتمسها في:

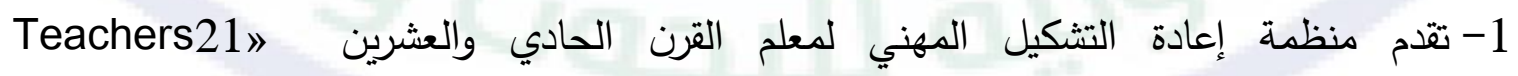
Reshaping the Profession of Teaching للتوجه نحو إعداد معلم القرن الحادي والعشرين يرتكز على التمهين الذي يُعطي المعلم الحرية

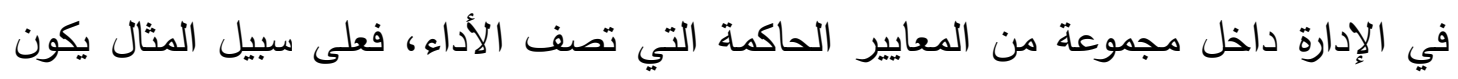




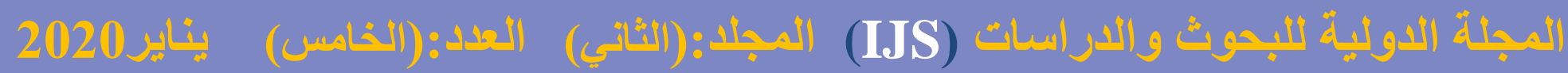

أ. د. رانيا الصاوي عبده عبد القوي، (عناصر العملية التعليمية ومهارات معلم القرن الحادي والعشرين).

المعلم هو الخبير المهني في إدارة عمليات التقويم، وليس المختص بإعداد ورقة الاختبار فقط، وتتدرج هذه المهنية في كافة المهارات التدريسية التي يديرها معلم القرن الحادي والعشرين.

2- يشير مشروع »Things for the 21st Century Project 21 بالولايات المتحدة الأمريكية National Educational » والقائم على المعايير الوطنية للتكنولوجيا التعليمية للمعلمين Technology Standards for Teachers والعشرين متمثلً في أن يكون المصمم والمقيم والمشارك في إنتاج تكنولوجيا التعليم، بما تشمله من استخدام شبكة الإنترنت والتعليم عن بعد، وإنتاج البرامج التعليمية وبرامج المحاكاة.

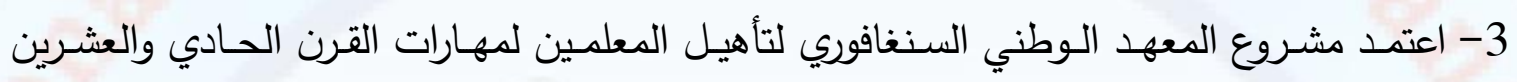
،st Century teachers call for 21st Century Teacher Educators21» Teacher Education for the 21st Century: A Singapore Model

$$
\begin{aligned}
& \text { المهارات التي هدف إليها المركز في: } \\
& \text { - - مهارات فن التدريس (فن التعليم). } \\
& \text { - مهارات إدارة البشر - } \\
& \text { - مهارات إدارة الذات. } \\
& \text { - مهارات إدارية وتنظيمية. } \\
& \text { - مهارات التواصل. } \\
& \text { - مهارات التيسير - } \\
& \text { - مهارات تكنولوجية. } \\
& \text { - - مهارات التفكر } \\
& \text { - - مهارات الابتكار وروح المبادرة. } \\
& \text { - مهارات اجتماعية وذكاء وجداني. }
\end{aligned}
$$

4-تقدم منظمة educational-origami المهتمة بالتعليم القائم على دمج المعرفة بالتكنولوجيا والتواصل Information and Communication Technologies (ITC) تحديدًا لأهم 


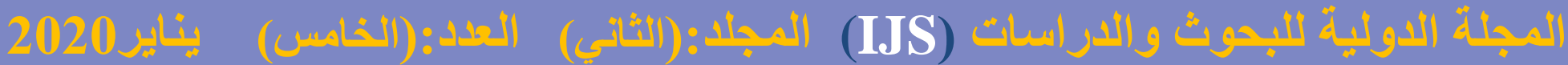

أ. د. رانيا الصاوي عبده عبد القوي، (عناصر العملية التعليمية ومهارات معلم القرن الحادي والعشرين).

هُتفادي المخاطر (The Risk taker): الذي يتفادى مصادر المخاطر المتمثلة في فقد

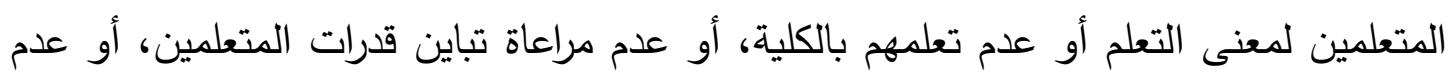

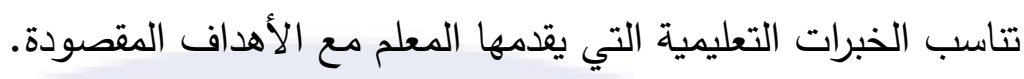

• الُمتضامن (The Collaborator): الذي يتحمل المسئولية التضامنية مع المتعلمين ومؤسسة

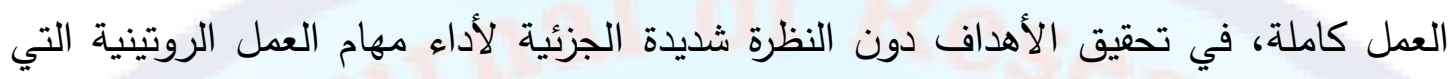
تكفيه شر العقوبات.

• النموذجي (The Model): الذي يمثل قدوة لزملائه في العمل المخلص لتقديم تعليم يتميز بالجودة، كما يمثل المعلم نموذجًا لطلابه في القيم الخلقية والمثابرة العلمية. • القائد (The Leader): الذي يمثل قائًا يدير طلابه من حيث قدراتهم، وأنماطهم المختلفة، ومكوناتهم الثقافية المتباينة إلى الدرجة التي تجعل الطالب متحدًا مع معلمه (قائده). • المستبصر (The Visionary): الذي يمتلك رؤيا تطويرية لذاته المهنية ولمؤسسة العمل ككل، وهو قادر على توضيح تلك الرؤيا والعمل على تحقيقها قدر المستطاع دون الاكتفاء بتتفيذ الأوامر أو الاعتراض عليها جزئيًا أو كليًا.

•المتعلم (The Learner): من خلال تطوير المعلم لكفاياته المهنية والأكاديمية بصورة ذاتية أو جاون نظامية حسب البدائل المكنة، وكذلك الالتحاق بالبرامج التدريبية المختلفة. •المحاور (The Communicator): الذي يهيئ البيئة التعليمية الحرة ليناقش طلابه ويحاورهم ويشجع روح المبادرة والتلقائية. • المهيأ (The Adaptor): من خلال تهيئة بيئة التعلم والمتعلمين والخبرات التعليمية وأدوات التقييم بصورة نظامية قابلة للانسجام التلقائي بين عناصرها لتحقيق الأهداف المقصودة.

\section{المصدر الثاني: التوجهات التربوية المستقبلية.}

في سبيل تحقيق المعلم لنسب متقدمة من احتفاظ المتعلمين بتعلمه، وبالتالي إمكانية استخدامه بصورة أكثر (دينامية - تفاعلية) لابد أن يقوم معلم القرن الحادي والعشرين بدوره في إدارة عملية التعليم وإدارة التكنولوجيا المستخدمة وإدارة استخدام المتعلمين للمعرفة، وإدارة المهارات الحياتية وإدارة قدراتهم. 


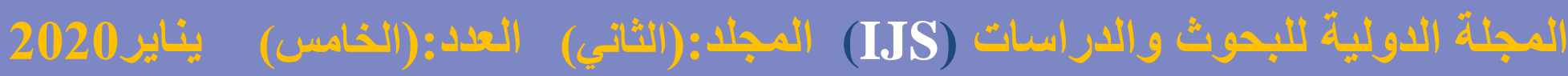

أ. د. رانيا الصاوي عبده عبد القوي، (عناصر العملية التعليمية ومهارات معلم القرن الحادي والعشرين).

\section{المصدر الثالث: مهارات المتعلم المطلوبة في القرن الحادي والعشرين.}

Partnership for Century 21 استنادًا لما قدمته منظمة الثراكة من أجل مهارات القرن

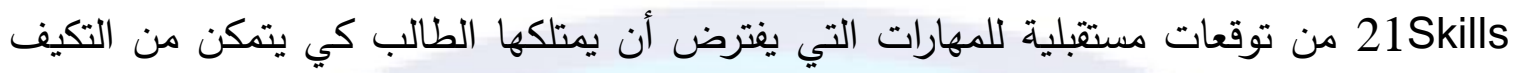

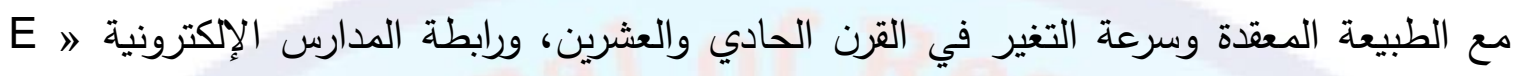
SChool News

• المسؤولية والتوافق: وتثير إلى قررة الفرد على تطوير ذاته بما يتوافق مع بيئة العمل والبيئة

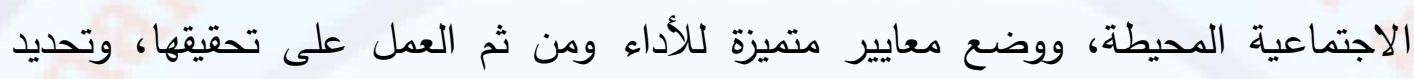
الأهداف الشخصية وكذلك الأهداف المتوقعة للآخرين.

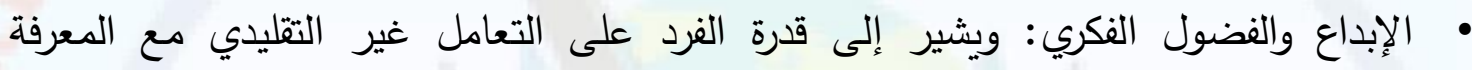

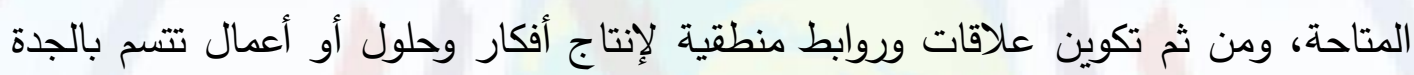
والتميز عما يقدمه الآخرون. مهارات التواصل: وتثير إلى قدرة الفرد على التواصل الفعال مع ذاته والآخرين، ومن ثم الفي التواصل مع المجتمع بكافة أنماط التواصل المككنة اللفظية وغير اللفظية، مع استخدام كافة التهات الوسائل والتقنيات الديثة لتحقيق التواصل المتميز . • • التنكير النقدي وفكر النظم: ويشير إلى قدرة الفرد على تقدير الحقيقة من خلال مقدمات منطقية، ومن ثم الوصول إلى اتخاذ القرارات السليمة في ضوء تقييم المعلومات وفحص الآراء المتاحة والأخذ بعين الاعتبار وجهات النظر المختلفة.

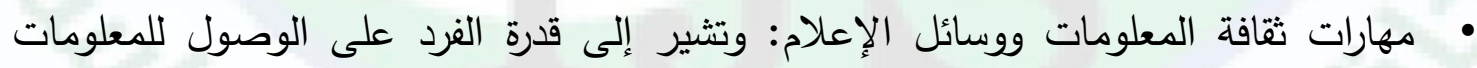
المختلفة من كافة المصادر الموثوقة التي تتيحها التتنيات المختلفة، ويرتبط بذلك قدرة الفرد على الاستخدام الأمثل للمعلومات في عصر الاقتصاد المعرفي.

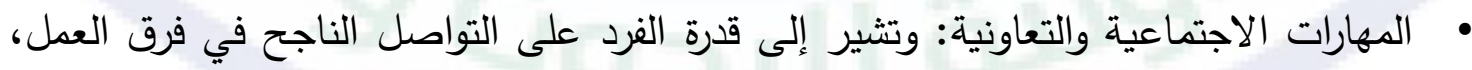

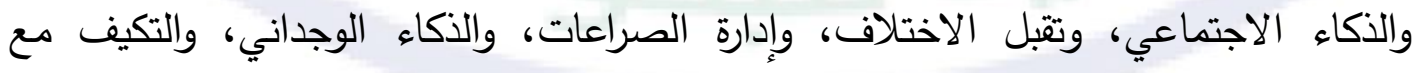
الأدوار والمسئوليات. • تحديد المشكلة وصياغة الحل: وتثير إلى قدرة الفرد على التحديد الدقيق للمشكلات وصياغتها علميًا، وتحديد بدائل الحل الممكنة، وتجريها وانتقاء الأنسب منها، وتحديد الحلول المتميزة. 


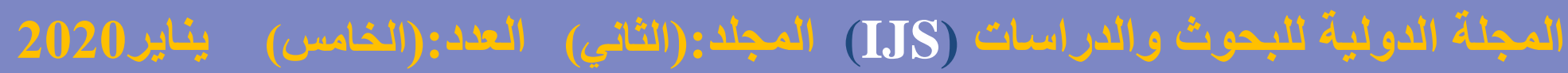

أ. د. رانيا الصاوي عبده عبد القوي، (عناصر العملية التعليمية ومهارات معلم القرن الحادي والعشرين).

• التوجيه الذاتي: وتثير إلى قدرة الفرد على تقييم مدى فهمه لاحتياجاته التعليمية الخاصة،

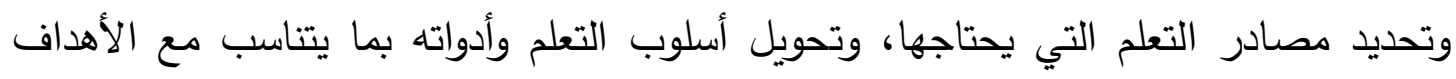

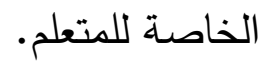

• الدسؤلية الاجتماعية: وتثير إلى قدرة الفرد على تحمل مسؤولية العمل الفردي تجاه

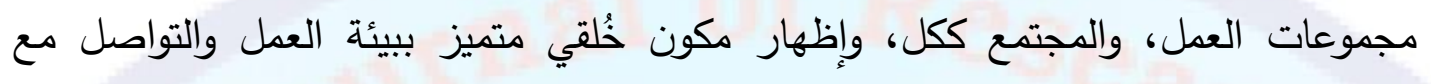

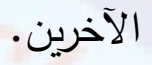

وفي ضوء ما تقدم للمصادر الثلاث لاشتقاق مهام معلم القرن الحادي والعشرين يمكن تحديد

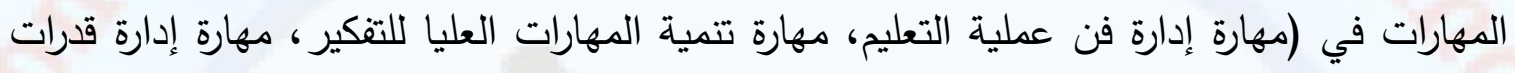

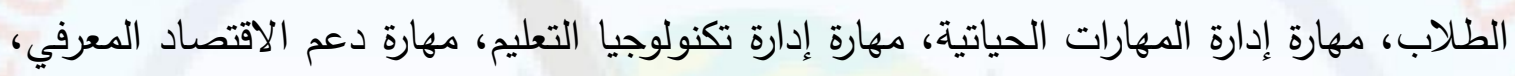
مهارة إدارة منظومة التقويم). ويُلاحظ على تلك المهارات: - - توافقها مع الصصادر الثثلاث السابق عرضها. - شمولها للعمليات المهنية التي يقوم بها المعلم، حيث اهتمت بعض التوجهات التهات بعض الفنيات لمعلم القرن الحادي والعشرين دون فنيات أخرى. - ت تباينها عن العمليات التقليدية التي يقدمها المعلم التقليدي.

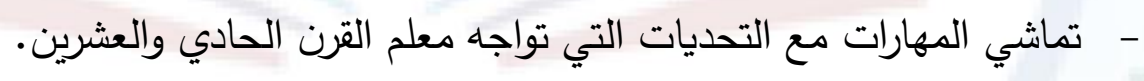




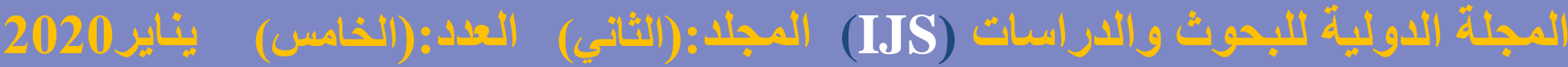

أ. د. رانيا الصاوي عبده عبد القوي، (عناصر العملية التعليمية ومهارات معلم القرن الحادي والعشرين).

لذا فهناك العديد من المهارات التي ينبغي أن يمتلكها معلمو القرن الحادي والعشرين لولوج عصر الاقتصاد المعرفي سعيًا لبناء مجتمع المعرفة في ضوء التحديات المتعددة التي تعيشها

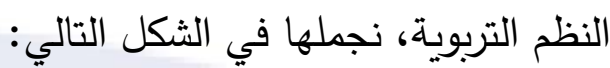

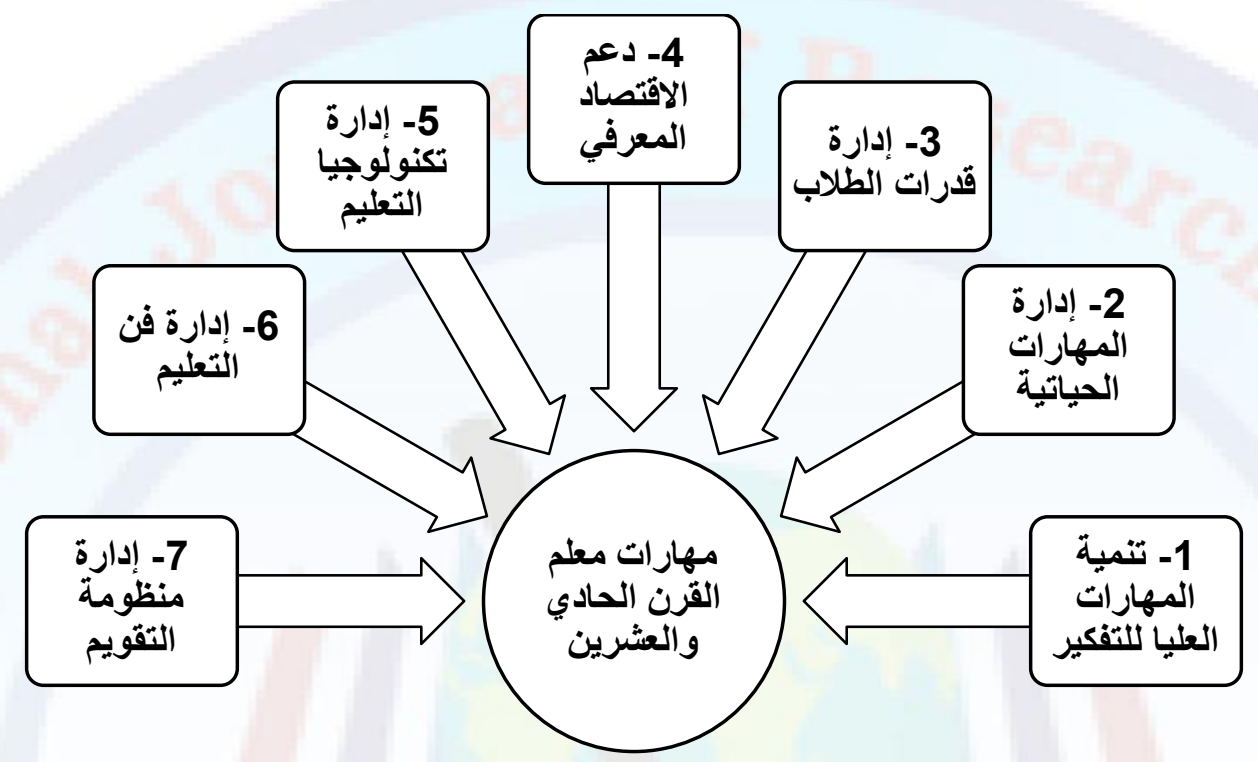

شكل (4) مهارات معلم القرن الحادي والعشرين.

المهارة الأولى: تنمية المهارات العليا للتفكير.

تعد مهارات التفكير من العمليات الأساسية في السلوك الإنساني، فهي السمة المميزة للإنسان عن غيره من الكائنات الأخرى، وأصبحت برامج تعليم التفكير وتتميته هدفًا رئييًا من أهداف المؤسسات التربوية، وعليه فإن الكثير من القائمين على العملية التعليمية يتفقون على ضرورة تعليم التتكير وتتمية مهاراته لاى المتعلمين، خاصة أن هناك دولاً تبنت هذه الوجهة في عملياتها التعليمية

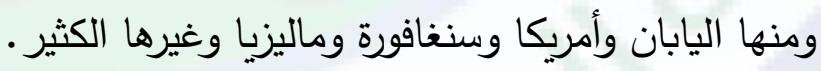

ولعل المتتبع لاتجاهات تعليم وتعلم التقكير يلمس اختلافًا واضحًا بين المنظرين في هذا المجال، إذ إن هناك اتجاهات متباينة حول هذا الموضوع، إذ يُعتبر المعلم حسب معطيات القرن الحادي والعشرين مسؤولًا مباشرًا عن تتمية أنماط التنكير لاى المتعلمين. 


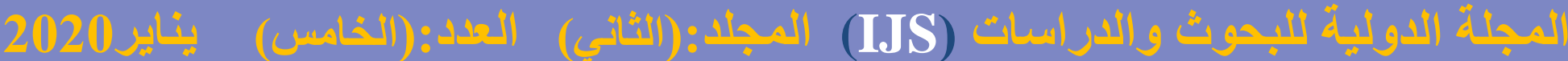

أ. د. رانيا الصاوي عبده عبد القوي، (عناصر العملية التعليمية ومهارات معلم القرن الحادي والعشرين).

تتتوع برامج تعليم التفكير بحسب الاتجاهات النظرية والتجريبية التي تتاولت موضوع التنكير، ومن أبرز الاتجاهات النظرية التي بنيت على أساسها برامج تتمية التنكير ومهاراته كما أشار (مجيد، 2008) وأوضحها في الثكل التالي:

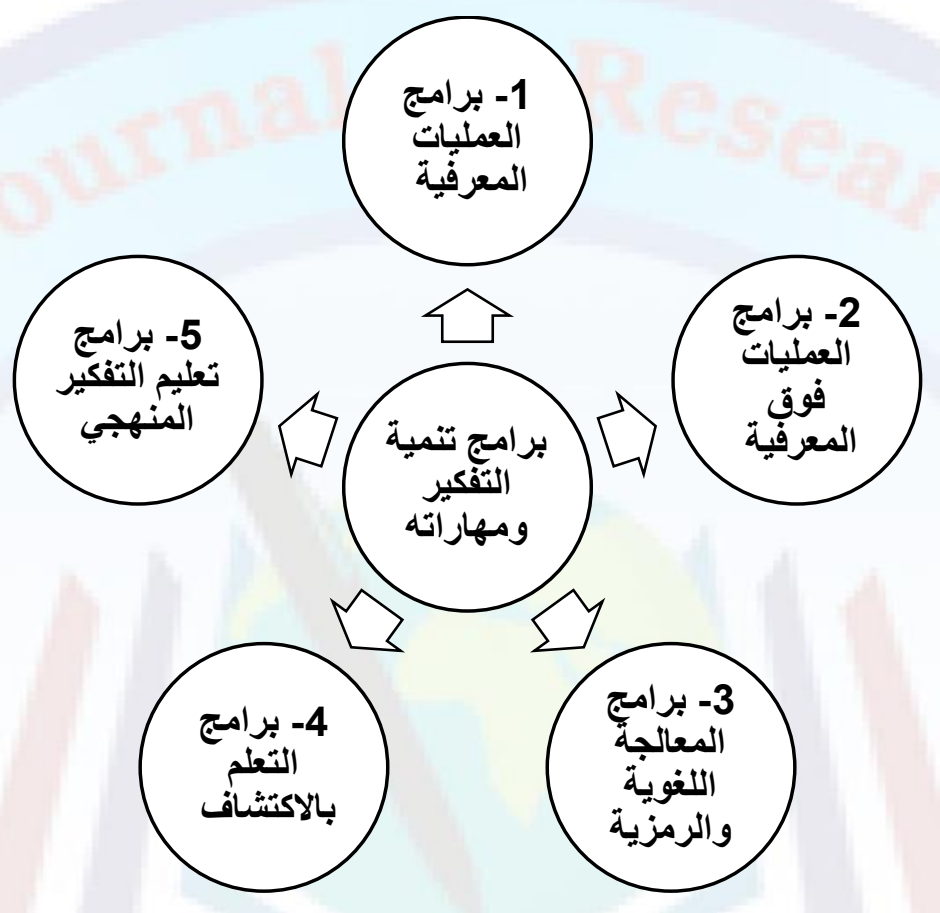

شكل (5) برامج تنمية التفكير ومهاراته.

وضمن أولويات أنماط مهارات التنكير العليا بالقرن الحادي والعشرين تتنبأ الأدبيات بثلاثة أنماط لمهارات التفكير العليا ينبغي على معلم القرن الحادي والعشرين مراعاتها، وقد أشار (سعادة:2015) إلى أن هناك أولويات لأنماط مهارات التثكير يمكن توضيحها في الثكل التالي:

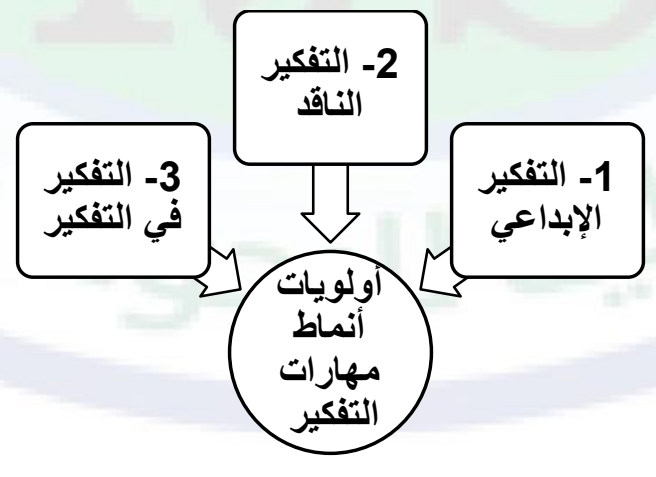

شكل (6) أولويات أنماط مهارات التفكير. 


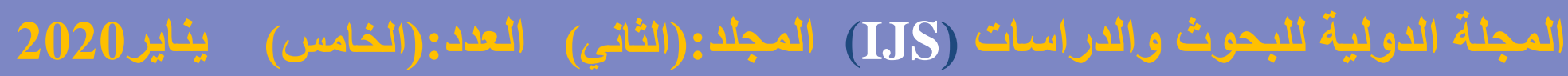

أ. د. رانيا الصاوي عبده عبد القوي، (عناصر العملية التعليمية ومهارات معلم القرن الحادي والعشرين).

يعد الاهتمام بأنماط مهارات التفكير المختلفة من أهم المؤثرات على العملية التربوية والتعليمية.

\section{المهارة الثانية: إدارة المهارات الحياتية.}

Hidden تناولت الأدبيات التربوية في توصيفها لمناهج المستقبل، المنهج الخفي Curriculum

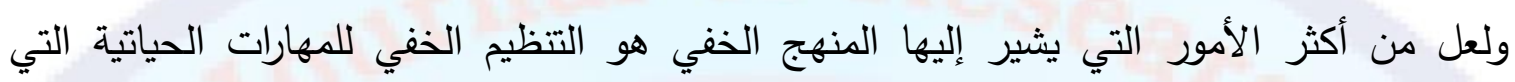
يكتسبها المتعلم من قبل المعلم، فصحيح أن المعلم يدخل إلى الحجرة الدراسية ليعلم طلابه أكاديميات

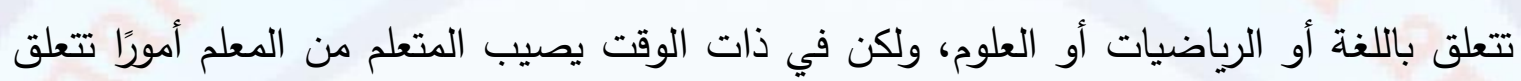
بطريقة التواصل وإدارة التعامل ومهارات الذات.

ومن هنا تؤكد أدبيات القرن الحادي والعشرين على الكثير من المهارات الحياتية التي ينبخي على المعلم أخذها بعين الاعتبار في تعليمه لطلابه، بحيث تخرج من حيز المنهج الخفي إلى حيز المنهج المُعلن، بل تذهب بعض الاتجاهات إلى ما هو أبعد من ذلك بأن يكون ضمن المناهج الدراسية مقررات مستقلة تحت مسمى المهارات الحياتية.

ولكي يتمكن المعلم من تنمية مثل هذه المهارات ينبغي عليه إعداد مواقف تدريبية مقصودة على المهارة والتشجيع على استخدامها لإتقان مهارة ما يحتاج الطلاب لأن يتدربوا عليها مرارًا وتكرارًا، وأوضح كل من: (سعد الدين:2007، عبد المعي، ومصطفى:2008) أن المعلم يمكنه أن يوجه

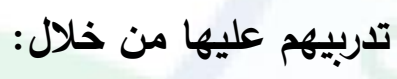

• تعيين المهارة إما كدور محدد يقوم به طلاب معينون أو كمسئولية عامة يتعين على جميع أعضاء المجموعة أن ينخرطوا فيها. • ملاحظة كل مجموعة وتسجيل أي الأعضاء ينخرطون في المهارة.

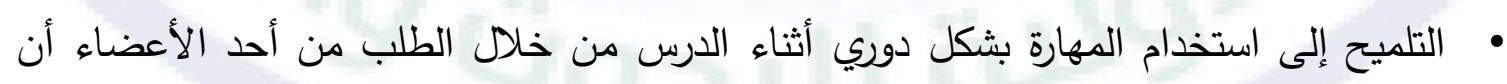
يقدم عرضًا لاستخدامها. • التدخل في المجموعات التعليمية من أجل توضيح طبيعة المهارة وكيفية الانخراط فيها. • تدريب الطلاب لتحسين استخدامهم للمهارة. 


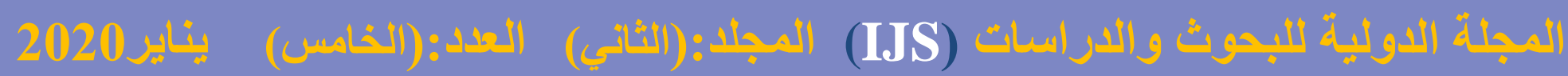

أ. د. رانيا الصاوي عبده عبد القوي، (عناصر العملية التعليمية ومهارات معلم القرن الحادي والعشرين).

• • التأكد من أن كل طالب يحصل على التغذية الراجعة حول استخدامه للمهارة ويتأمل كيفية الانخراط في المهارة بفعالية أكثر في المرة القادمة.

المهارة الثالثة: إدارة قرات الطلاب.

إدارة القدرات من خلال مفهوم الذكاءات الدتعدة، حيث أن الذكاء وفق جاردنز عبارة عن

إمكانية بيولوجية تجد تعبيرها فيما بعد كنتاج للتفاعل بين العوامل التكوينية والعوامل البيئية.

يختلف الناس في مقدار الذكاء الذي يولدون به، كما يختلفون في طبيعته، كما يختلفون في

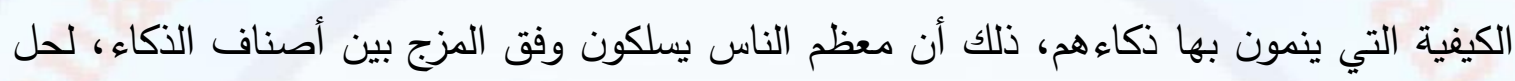
مختلف المشكلات التي تعترضهم في الحياة.

يظهر الذكاء بشكل عام لاى معظم الناس بكيفية تشترك فيها كل الذكاءات الأخرى، وبعد الطفولة المبكرة لا يظهر الذكاء في شكله الخاص.

إن نظرية الذكاءات المتعدة تسمح للثخص باستكثاف مواقف الحياة المعيشية والنظر إليها وفهمها بوجهات نظر متعدة، فالثخص يمكنه أن يعيد النظر في موقف ما عن طريق معايشته

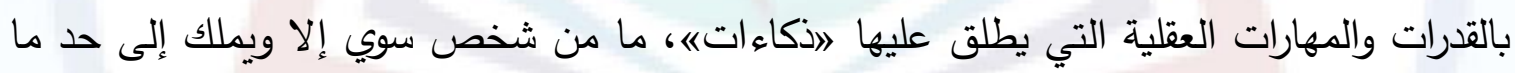

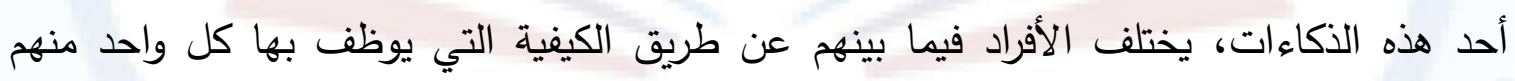

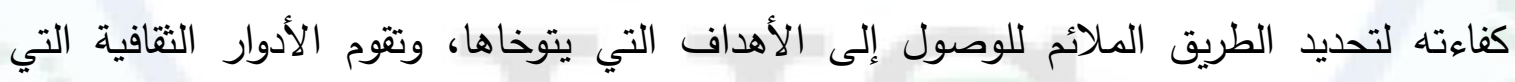
يضطلع بها الفرد في مجتمعه بإكسابه عدة ذكاءات.

ومن الأهمية بمكان اعتبار كل فرد متوفرًا على مجموعة من الاستعدادات وليس على قدرة

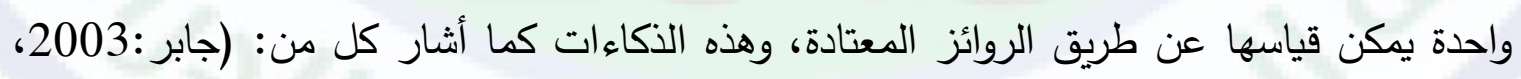
أبو هاشم:2007) هي: (الذكاء اللغوي- الذكاء المنطقي - الرياضي - الذكاء التفاعلي- الذكاء

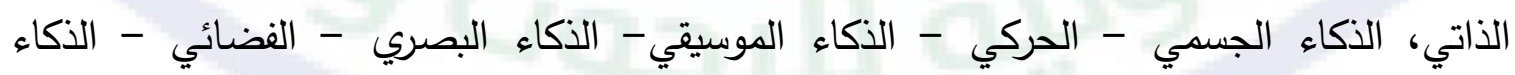
الطبيعي). 


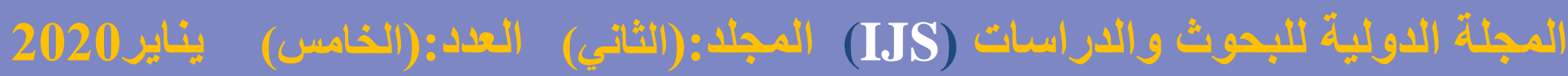

أ. د. رانيا الصاوي عبده عبد القوي، (عناصر العملية التعليمية ومهارات معلم القرن الحادي والعشرين).

\section{المهارة الرابعة: دعم الاقتصاد المعرفي.}

المستقبل زاخر بالمعارف التي لا حصر ولا عد لها، وعلى الإنسان العمل والتنكير متعاونًا

أو متنافيًا للكثف عنها وتوظيفها والاستفادة منها، فالمستقبل في التتمية الاقتصادية مرهون بدرجة الإسيان كبيرة بقدر ما تمتلك الأمم من معارف وقدر ما تستطيع أن تدير هذه المعارف في بانوراما الإنتاج. فلقد تبدلت معادلة الإنتاج.

ويرجع ذلك لظهور مفهوم الاقتصاد المعرفي (هو الاقتصاد الذي يلعب فيه توليد المعرفة واستثمارها الدور الأكبر في إيجاد الثروة)، في عصر الثورة الصناعية أوجدت الثروة عبر استثمار الثراد

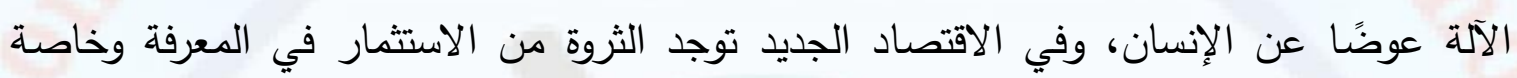
التكنولوجيا المتقدمة). ومن أهم ظواهر الاقتصاد العالمي المبني على الهي المعرفة كما أوضحها (الزهراني، إبراهيخ: 2012) في النقاط الآتية: • • مرعة توليد ونشر واستثمار المعرفة. • • زيادة في البيئة التنافسية العالمية. • زيادة أهمية ودور المعرفة والابتكار في الأداء الاقتصادي وفي تراكم الثروة. • تحرير التجارة، وتزايد نسبة التكنولوجيا في الصادرات. • عولمة الإنتاج. • زيادة دور التعليم والتدريب.

لذا يكمن دور النظام التربوي في تهيئة الطلاب لمجتمع الاقتصاد المعرفي كما أشار (أبو نعير وآخرون، 2011): (1) 142

$$
\begin{aligned}
& \text { - } \\
& \text { - تمكين الفرد من توظيف تكنولوجيا المعلومات والاتصالات. }
\end{aligned}
$$
- تتمية القدرة على الفهم المتعمق والتفكير الناقد والتحليل والاستتباط. - تعزيز القدرة على إحداث التغيير والتطوير • 


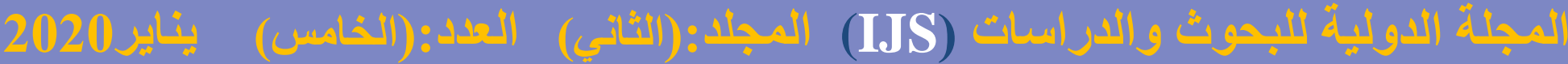

أ. د. رانيا الصاوي عبده عبد القوي، (عناصر العملية التعليمية ومهارات معلم القرن الحادي والعشرين).

$$
\text { - تعزيز القدرة على الحوار الإيجابي والنقاش الهادف وتقبل آراء الآخرين. }
$$

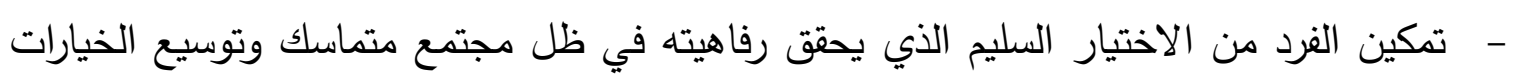

$$
\text { والفرص المتاحة أمامه. }
$$

وفي ضوء النقاط السابق ذكرها تتحدد أولويات التطوير التربوي المنشود في التعلم المستمر مدى الحياة والاستجابة لتطوير الاقتصاد وتلبيه متطلباته، والوصول إلى تكنولوجيا المعلومات والاتصالات

$$
\text { الحديثة والتعلم النوعي، وتحسين نوعية التعلم. }
$$

لذا تتحدد الأدوار المطلوبة من معلم القرن الحادي والعشرين لدعم الاقتصاد المعرفي من خلال إتقان أداء مجموعة من الأدوار كما أثار إليها كل من: (أبو نعير وآخرون: 2011، الزهراني،

$$
\text { إبراهيم: 2012) منها: }
$$

• تحقيق التعلم الفعال بأقصى مشاركة للطلبة.

• التتويع في أساليب التعلم لتوائم الحاجات المتتوعة للطلبة، وتراعي الفروق الفردية بينهم.

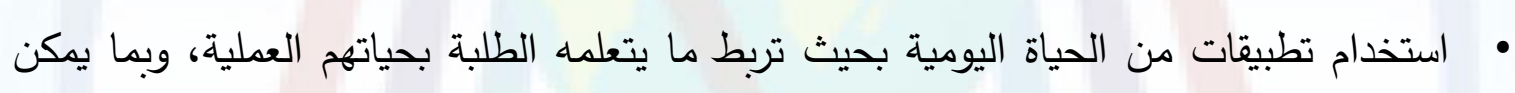
البناء عليه مستقبلًا.

• الاستجابة لمستويات عليا من الأسئلة (مثل: التطبيق، التحليل، التركيب، التقويم). • قضاء وقت أكبر في مناقثة النشاطات التي ينخرطون فيها بأفكارهم.

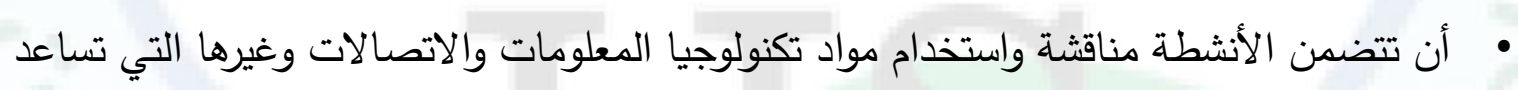
على إدراك المفهوم الجديد. • • تقديم أنشطة تعزز التعلم من خلال العمل. • تطوير أنشطة لتتمية روح العمل الجماعي واستخدام المهارات البين شخصية إضافة إلى أنثطة التعلم الفردية. • استخدام فعاليات وخبرات تثجع الطلبة على التعاون. • توفير العروض التثيلية المرئية والثفوية والمجسمة. 


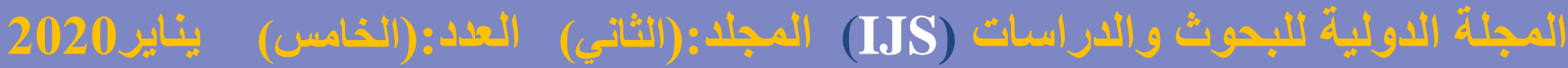

أ. د. رانيا الصاوي عبده عبد القوي، (عناصر العملية التعليمية ومهارات معلم القرن الحادي والعشرين).

\section{المهارة الخامسة: إدارة تكنولوحيا التعليم.}

في ظل ثورة المعلومات والتقدم التكنولوجي، لم يعد للمعلم النمطي الذي عهدناه كنموذج للقدرة العالية على تحصيل العلم بهدف توصيلها أو نقلها لعقول التلاميذ، مكانًا يذكر في النظم التعليمية الحديثة، حيث أصبح تطبيق الفكر العلمي والأساليب التكنولوجية الحديثة في تصميم لتهي الخطط والبرامج التعليمية ضرورة تحتمها المرحلة الحالية التي يمر بها قطاع التعليم والذي يعاني من

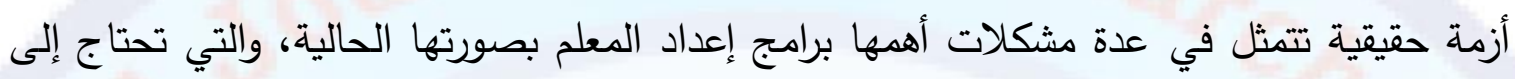
تطوير وتحديث في الفكر والاستراتيجيات القائمة عليها. إن المتوقع لمعلم القرن الحادي والعشرين، كما أوضح كل من: (التودري: 2009، بلقاسم،

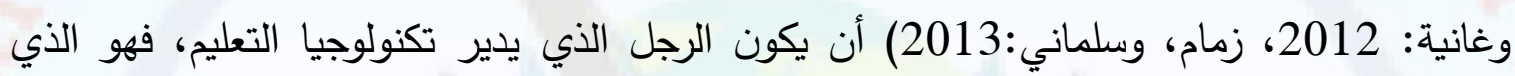
يحكم على جودة البرامج التعليمية، بل ويشارك في إنتاجها باعتباره المرجعية الأكاديمية للمواد التعليمية.

فالمعنى المقصود أن يشارك معلم القرن الواحد والعشرين في إدارة منظومة تعليمية لتقديم البرامج التعليمية أو التدريبية في أي وقت وفي أي مكان باستخدام تقنيات المعلومات والاتصالات التفاعلية، مثل الإنترنت، الإذاعة، القنوات المحلية أو الفضائية، الأقراص المدغنطة، التليفزيون، لئية البريد الإكتروني، أجهزة الكمبيوتر، المؤتمرات عن بعد؛ وذلك لتوفير بيئة تعليمية تفاعلية متعددة

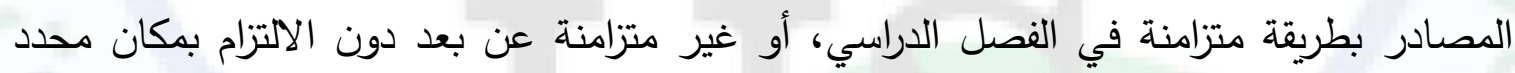
اعتمادًا على التعلم الذاتي والتفاعل بين المتعلم والمعلم. 


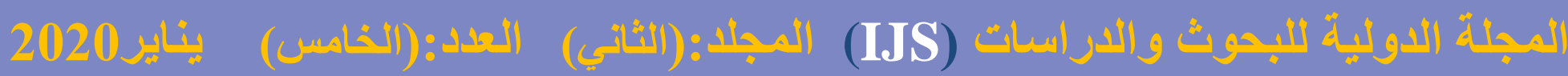

أ. د. رانيا الصاوي عبده عبد القوي، (عناصر العملية التعليمية ومهارات معلم القرن الحادي والعشرين).

ونلخص أهمية التعليم الإكتروني لمعلم القرن الحادي والعشرين كما أوضحها كل من: (الزهراني، إبراهيم: 2012) في الثكل التالي:

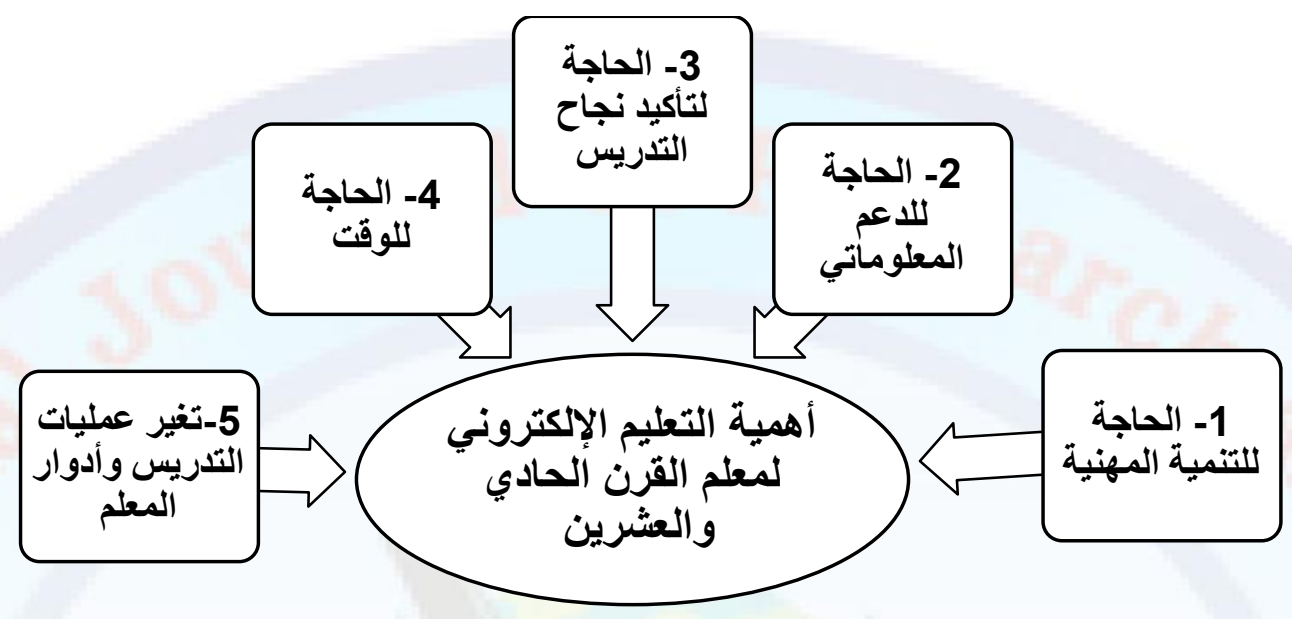

شكل(7) أهمية التعليم الإكتروني لمعلم القرن الحادي والعشرين.

\section{ولضمان نجاح صناعة التعليم الإكتروني بيِ عمل ما يلي:}

هناك العديد من الأساليب لضمان نجاح صناعة التعليم الإكتروني كما أشار كل من: (الغراب:2003، سالم:2004، فرج، 2005، الموسى، وعبد الله: 2005، عبد العزيز : 2008) في

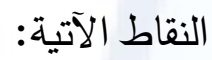
- - التعبئة الاجتماعية لدى أفراد المجتمع للتفاعل مع هذا النوع من التعليم. - - ضرورة مساهمة التربويين في صناعة هذا التعليم. - - توفير البنية التحتية لهذا النوع من التعليم وتتمثل في إعداد الكوادر البشرية المدربة، وكذلك توفير خطوط الاتصالات المطلوبة التي تساعد على نقل هذا التعليم من مكان لآخر . - - وضع برامج لتدريب الطلاب والمعلمين والإداريين للاستفادة القصوى من التقنية. المهارة السادسة: إدارة فن عملية التعليم.

شهدت نهاية القرن العشرين كما أوضح (شاهين:2011) ما هو أشبه بالثورة من خلال

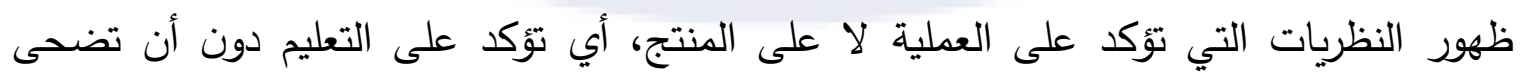

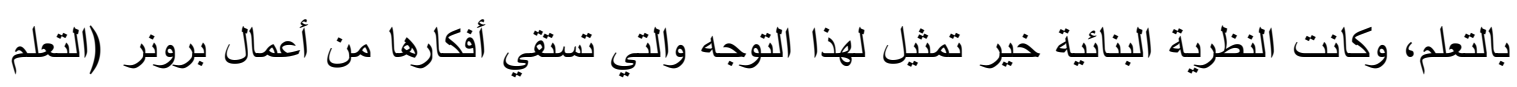




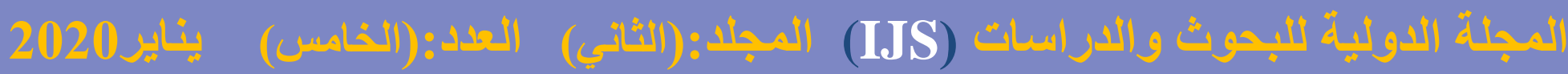

أ. د. رانيا الصاوي عبده عبد القوي، (عناصر العملية التعليمية ومهارات معلم القرن الحادي والعشرين).

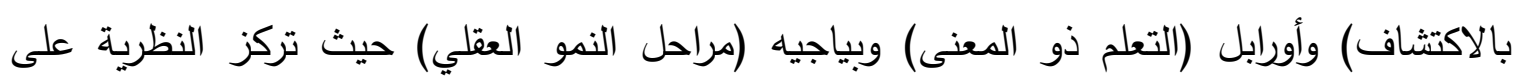

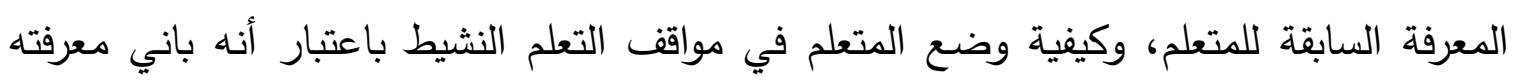
بنفسه لإزالة التتاقض أو إكمال النقص المعرفي، وكيفية حدوث الترابط بين المعرفة الجديدة والمعرفة السابقة مما يؤدي لإعادة تثكيل البنية المعرفية للمتعلم.

لذا المطلوب من معلم القرن الحادي والعشرين أن يرعى كيفية إدارة الموقف التعليمي (علية

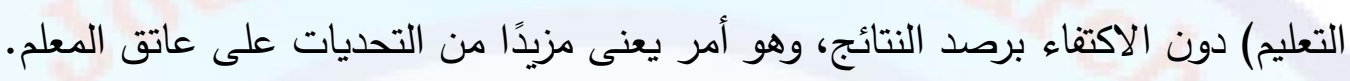
المهارة السابعة: إدارة منظومة التقويم.

مع أهمية التقويم في تحقيق جودة التعليم إلا أنه يُلاحظ في كثير من الأنظمة التعليمية أنه

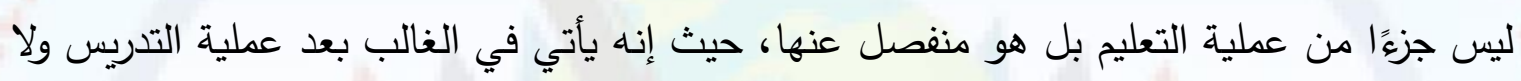

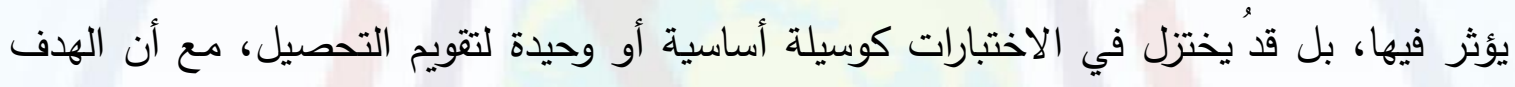
الرئيس للتقويم التربوي هو ضمان جودة العملية التربوية ونواتجها.

وذلك لأن الغرض من جهود المؤسسات التربوية هو إكساب الطلاب والطالبات، وبقية

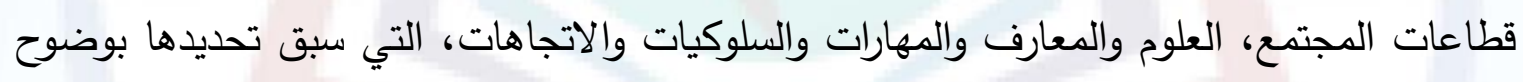

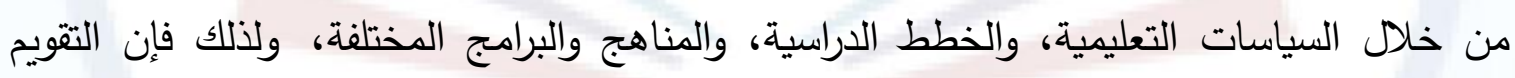

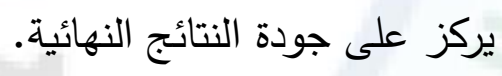

ومن هنا فإن التقويم سوايٌ أكان تقويمًا مستمرًا تكوينيًا (Formative) أم تتويمًا

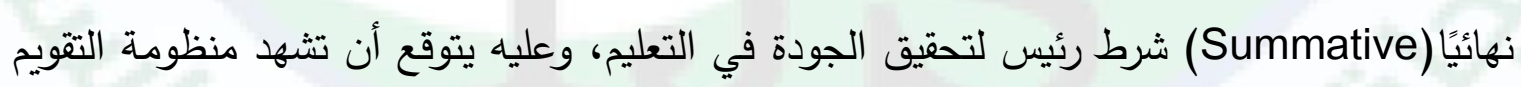

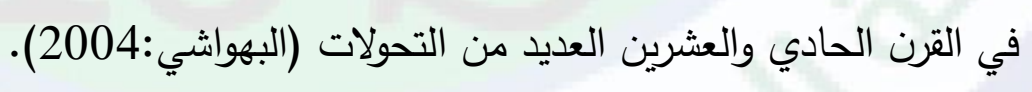

حتى يُحقق طلابنا النجاح في القرن الواحد والعشرين، نحن بحاجة إلى مجموعة من

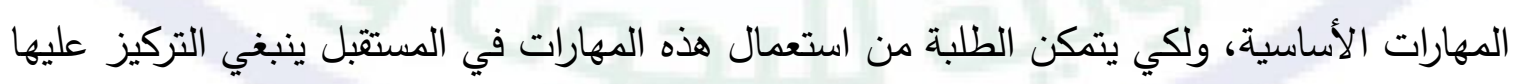
وتطويرها في كل ما يمكن أن يمر به الدتعلّم من تفاعلٍ دراسي وخبراتٍ في التعليم.

146 كما يعتقد البعض أن الحديث عن تطوير المعلم وإعادة تأهيله هو نوع من الترف العلمي أو

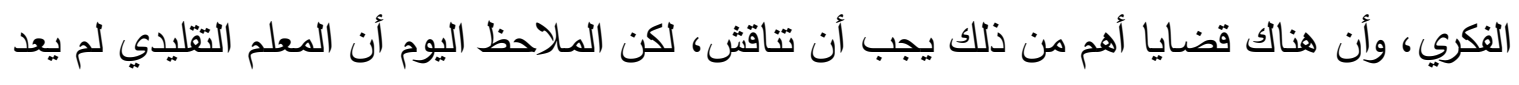




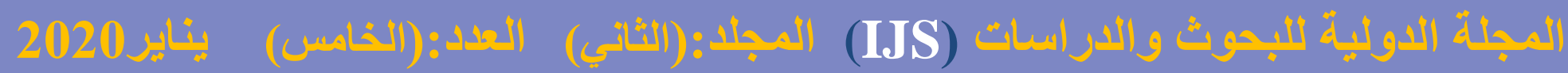

أ. د. رانيا الصاوي عبده عبد القوي، (عناصر العملية التعليمية ومهارات معلم القرن الحادي والعشرين).

له مكان في العملية التعليمية وسط السياقات التربوية الحديثة في مجال التربية والتعليم واستراتيجيات التدريس الجديدة.

فقد غيرت النظريات الحديثة في التربية النظرة لدور كل من المعلم والطالب، وغيرت أيضا نمط التفاعل التقليدي الذي كان سائد الفترات طويلة من الزمن، فأصبحت للمعلم مهام أخرى غير التلقين والإلقاء وأصبح للطالب أدوار أخرى كثيرة غير الحفظوالاستماع والتكرار السلبي للمعلومة. وأصبح المعلم اليوم مطالبا بتنمية مهاراته التدريسية بجودة وكفاءة أكثر من ذي قبل، وأن يدرك أن من مهامه الجديدة أن يكون موجها وميسرا ومساعدا للطلاب لكي يتعلموا بأنفهم، وأن

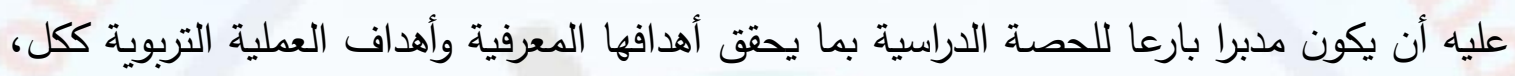
ولهذا أرى أنه من المفيد الإثارة إلى أهم المهارات التي يحتاج إليها المعلم لجعل العملية التربوية أكثر فائدة ومتعة.

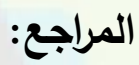

1. أبو العنين، علي خليل وآخرون. (2004). تأملات في علوم التربية كيف نفهها، مكتبة الدار الهندسية، القاهرة، جمهورية مصر العربية.

2. أبو نعير، نذير سيحان، والسرحان، خالد علي، والزبون محم سليم. (2011). مفهوم الاقتصاد المعرفي وأدوار المعلمين المتجددة خلاله من وجهة نظر معلمي المرحلة الثانوية في الأردن وعلاقة ذلك ببعض المتغيرات، مجلة دراسات، العلوم التربوية، المجلد (38)، العدد (1)،

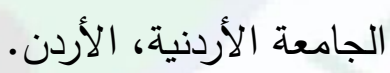
3. أبو هاشم، السيد. (2007). البناء العاملي للذكاء في ضوء تصنيف جاردنز وعلاقته بكل من الإدن فعالية الذات وحل المشكلات والتحصيل الدراسي لدى طلاب الجامعة، مجلة كلية التربية جامعة الزقازيق العدد (55)، جمهورية مصر العربية.

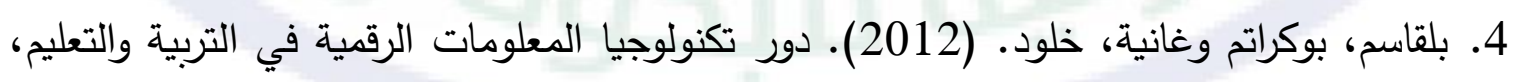
المؤتمر الدولي لتكنولوجيا المعلومات الرقمية، عمان، الأردن. 5. البهواشي، السيد عبد العزيز • (2004). تصور مقترح لتطوير النمو المهني في ضوه التغيرات المستقبلية في وظائف وأدوار المعلم وتجارب بعض الدول - المؤتمر السادس عشر الجمعية 


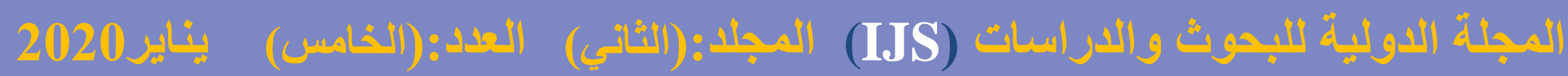

أ. د. رانيا الصاوي عبده عبد القوي، (عناصر العملية التعليمية ومهارات معلم القرن الحادي والعشرين).

المصرية للمناهج وطرق التدريس (تكوين المعلم) -دار الضيافة جامعة عين شمس، القاهرة،

$$
\text { جمهورية مصر العربية. }
$$

6. بوهني، نصرالدين الثيخ. (2014). العملية التربوية وتفاعل عناصرها وفق المقاربة بالكفايات، مجلة جامعة القدس المفتوحة للأبحاث والدراسات العدد 33 (2)، فلسطين. 7. التودري، عوض حسين. (2009). تكنولوجيا التعليم-مستحدثاتها وتطبيقات، دار الكتب، القاهرة، جمهورية مصر العربية. 8. جابر، جابر عبد الحميد. (2003). الذكاءات المتعددة والفهم، دار الفكر العربي، القاهرة، جمهورية مصر العربية.

9. جان، محم صالح · (1998). المناهج بين الأصالة والتغريب، دار الطرفين والمكتبة المكية، مكة المكرمة، المملكة العربية السعودية. 10. حبار، العالية. (2016). دور المعلم في اختيار الطرائق التعليمية الناجحة في التدريس، جامعة أبي بكر بلقايد، مجلة جسور المعرفة المجلد (2) العدد (6)، تلمسان، الجزائر. 11. الحربي، محم بن صنت (2011). خصائص البيئة التعليمة الجيدة، مقال، موقع مكتب التربية العربي، من:

http://www.abegs.org/Aportal/Post/Show?id=12751\&forumid=23

12. خطاب، أركان سعيد. (2012). التجديدات التربوية في العملية التعليمية، مجلة البحوث التربوية والنفسية، العدد 35، العراق

13. الخطيب، عالم الدين عبد الرحمن ـ (1988). الأهداف التربوية تصنيفها وتحديدها السلوكي، مكتبة الفلاح، الكويت.

14. الدريج، محمد. (2004). تحليل العملية التعليمية وتكوين المدرسين، منشورات سلسلة المعرفة للجميع، الرباط، الطبعة الثانية، المغرب.

15. زايد، نبيل محمد. (2013). التعليم والتعلُم -الكُعلّمِ والمُتعلّمِ في مدرسة المستقبل، مجلة دراسات تربوية ونفسية، العدد (79)، كلية التربية بالزقازيق، الزقازيق، جمهورية مصر العربية. 


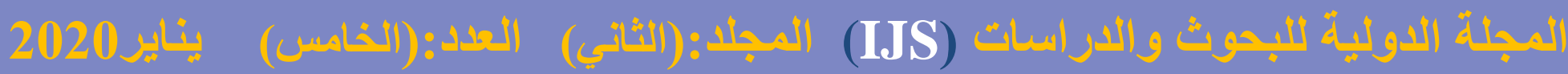

أ. د. رانيا الصاوي عبده عبد القوي، (عناصر العملية التعليمية ومهارات معلم القرن الحادي والعشرين).

16. زمام، نور الدين، وسليماني، صباح. (2013). تطور مفهوم التكنولوجيا واستخداماته في

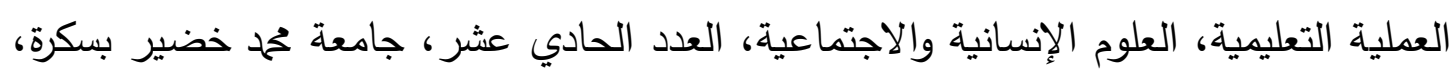
الجزائر

17. الزهراني، أحمد عوضه، إبراهيم، يحيي عبدالحميد. (2012). معلم القرن الحادي والعشرين، مجلة المعرفة، وزارة التربية والتعليم، المملكة العربية السعودية.

18. سات، تونيزيا.(2009). عناصر العملية التعليمية، منتديات تونيزيا سات، قسم ولهيه، التعليم والعلوم والتكنولوجيا، المنتدى التعليمي، من:

http://www.tunisia-sat.com/vb/showthread.php?t=595638

19. سالم أحمد محه. (2004). تكنولوجيا التعليم والتعليم الإكتروني، مكتبة الرشد، الرياض المملكة العربية السعودية.

20. سالم، أحمد. (2010). تحليل العملية التعليمة التعلمية، دقال تربوي، موقع المربي المتميز، http://belmamoune.ahlamontada.net/t1965-topic:من

21. سعادة، جودة أحمد ـ (1991). استخدام الأهداف التعليمية في جميع المواد الدراسية، دار الثقافة للنشر والتوزيع، القاهرة، جمهورية مصر العربية.

22. سعادة، جودت أحمد. (2015). تدريس مهارات التفكير، دار الثروق للنشر والتوزيع، القاهرة، جمهورية مصر العربية.

23. سعد الدين، هدى بسام تحمد. (2007م). المهارات الحياتية المتضمنة في مقرر التكنولوجيا للصف العاشر ومدى اكتساب الطلبة لها، رسالة ماجستير، الجامعة الإسلامية (غزة فلسطين)، كلية التربية، قسم مناهج وطرق تدريس - تكنولوجيا تعليم، فلسطين. 24. شاهين، عبد الحميد حسن عبدالحميد. (2011). استراتيجيات التدريس المتقدمة واستراتيجيات التعلم وأنماط التعلم، كلية التربية، جامعة الإسكندرية، جمهورية مصر العربية. 25. شريف، السيد عبد القادر • (2005). الأصول الفلسفية الاجتماعية للتربية، جامعة القاهرة، كلية رياض الأطفال، القاهرة، جمهورية مصر العربية. 26. صبري، ماهر إسماعيل. (2010). المناهج ومنظومة التعليم، مكتبة الرشد، الممكة العربية 


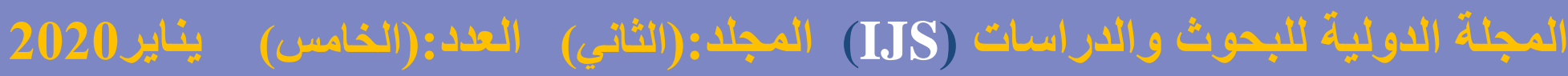

أ. د. رانيا الصاوي عبده عبد القوي، (عناصر العملية التعليمية ومهارات معلم القرن الحادي والعشرين).

27. عبد العزيز ، حمدي أحمد. (2008). التعليم الإكتروني، دار الفكر للطباعة والنشر، عمان، الأردن.

28. عبد المعطي، أحمد حسين، ومصطفى، دعاء حمح. (2008). المهارات الحياتية، مكتبة دار السحاب، القاهرة، جمهورية مصر العربية.

29. الغراب، إيمان محم. ( 2003). التعلم الإكتروني. مدخل إلى التدريب غير التقليدي، المنظمة العربية للتنمية الإدارية، القاهرة، جمهورية مصر العربية.

30. فرج، عبد اللطيف بن حسين. (2005). طرق التدريس في القرن الواحد والعشرين، دار المسيرة لنشر والتوزيع، عمان، الأردن.

31. كريم، محم أحمد، بدران، شبل. (1997). المناقثة في الأصول الفلسفية للتربية، الإسكندرية، مطابع الجمهورية، جمهورية مصر العربية.

32. مجيد، سوسن شاكر • (2008). تتمية مهارات التفكير الإبداعي الناقد، دار صفاء للطباعة والنشر والتوزيع، عمان، الأردن.

33. الموسى والمبارك، عبد الله، احمد. (2005). التعليم الإلكتروني والأسس والتطبيقات، مكتبة الرشد، الرياض، المملكة العربية السعودية.

34. Ananiadou, K. \& Claro, M. (2009). 21st century skills and competences for new millennium learners in OECD countries. Retrieved Sep. 28, 2015 , from http://www.oecd.org/officialdocuments/publicdisplaydocumentpdf/?cote= EDU/

35. Ananiadou, K. and M. Claro (2009). 21st century skills and competences for new millennium learners in OECD countries. OECD Education Working Papers, No. 41, OECD Publishing. Retrieved Sep. 28, 2015, from http://dx.doi.org/10.1787/218525261154 


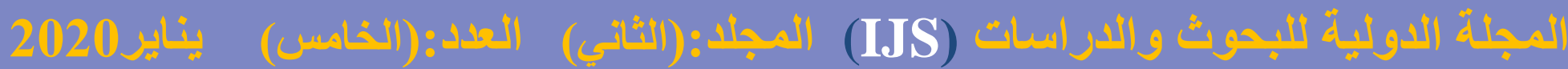

أ. د. رانيا الصاوي عبده عبد القوي، (عناصر العملية التعليمية ومهارات معلم القرن الحادي والعشرين).

36. Peat ،Mary (2000). Towards First Year Biology online: a virtual learning environment. Educational Technology \& Society. 3 (3): 203207. JSTOR jeductechsoci.3.3.203.

37. Safe Nasser Husain (2012). Online communication between home and school. Case study: Improving the usability of the Unicom e-service in the primary schools of Tier municipality" (PDF). Department of Informatics and Media.

38. Schleicher, A. (2013). Talents and education for international society in the future. Materials for Primary Education. (898), 14-19. (In Japanese) Trilling, B., \& Fadel, C. (2009). 21st century skills: Learning for life in our times. San Francisco CA: John Wiley \& Sons.

39. WKP(2009).20\&doclanguage $=$ enthralling, B., \& Fidel, C. (2009). 21st century skills: Learning for life in our times. San Francisco CA: John Wiley \& Sons. 


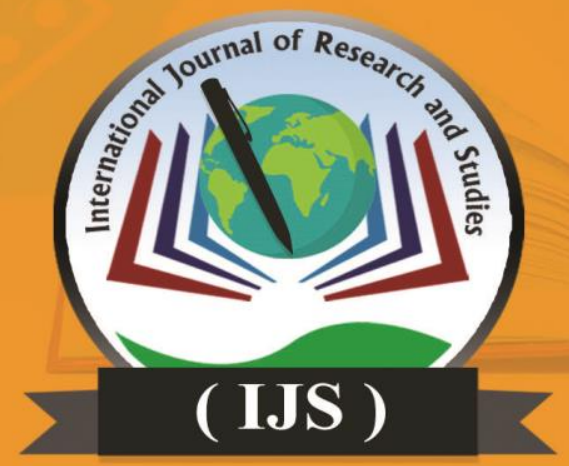

International Journal of Research and Studies

$$
\text { (IJS) }
$$

